\title{
Molecular Mimicry and Assemblies of Asymmetric Organic Semiconductors
}

\section{Craig Yu}

The University of Tokyo https://orcid.org/0000-0002-1423-5244

\section{Shohei Kumagai}

The University of Tokyo

\section{Michitsuna Tsutsumi}

The University of Tokyo

\section{Tadanori Kurosawa}

The University of Tokyo

\section{Hiroyuki Ishii}

University of Tsukuba https://orcid.org/0000-0003-0644-1424

Go Watanabe

Kitasato University https://orcid.org/0000-0001-6713-1249

\section{Daisuke Hashizume}

RIKEN https://orcid.org/0000-0001-7152-4408

Hiroki Sugiura

Fujifilm Corporation

\section{Yukio Tani}

Fujifilm Corporation

\section{Toshihiro Ise}

FujiFilm Corp.

Tetsuya Watanabe

Fujifilm Corporation

\section{Hiroyasu Sato}

Rigaku Corporation

Jun Takeya

University of Tokyo https://orcid.org/0000-0001-7377-6043

Toshihiro Okamoto ( $\square$ tokamoto@k.u-tokyo.ac.jp )

The University of Tokyo

Article 
Keywords: Charge Transports, Alkyl Chain Substitution, Molecular Fluctuations, Gauche Conformer, Isomorphic Structures

Posted Date: March 11th, 2021

DOI: https://doi.org/10.21203/rs.3.rs-273112/v1

License: (1) This work is licensed under a Creative Commons Attribution 4.0 International License. Read Full License 
2 Craig P. Yu ${ }^{1}$, Shohei Kumagai ${ }^{1}$, Michitsuna Tsutsumi ${ }^{1}$, Tadanori Kurosawa ${ }^{1}$, Hiroyuki Ishii ${ }^{2}$,

Watanabe $^{5}$, Hiroyasu Sato ${ }^{6}$, Jun Takeya ${ }^{1,7,8}$, Toshihiro Okamoto ${ }^{1,7,9 *}$

${ }^{1}$ Material Innovation Research Center (MIRC) and Department of Advanced Materials Science, Graduate School of Frontier Sciences, The University of Tokyo, 5-1-5 Kashiwanoha, Kashiwa, Chiba 277-8561, Japan

${ }^{2}$ Department of Applied Physics, Faculty of Pure and Applied Sciences, University of Tsukuba, 1-1-1 Tennodai, Tsukuba, Ibaraki 305-8573, Japan

${ }^{3}$ Department of Physics, School of Science, Kitasato University, 1-15-1 Kitasato, Minami-ku, Sagamihara, Kanagawa 252-0373, Japan.

${ }^{4}$ RIKEN Center for Emergent Matter Science (CEMS), 2-1 Hirosawa, Wako, Saitama 3510198, Japan

${ }^{5}$ FUJIFILM Corp., 577 Ushijima, Kaisei-machi, Ashigarakami-gun, Kanagawa 258-8577, Japan

${ }^{6}$ Rigaku Corp., 3-9-12 Matsubara-cho, Akishima, Tokyo 196-8666, Japan

${ }^{7}$ National Institute of Advanced Industrial Science and Technology (AIST)-University of Tokyo Advanced Operando-Measurement Technology Open Innovation Laboratory (OPERANDO-OIL), AIST, 5-1-5 Kashiwanoha, Kashiwa, Chiba 277-8561, Japan

${ }^{8}$ International Center for Materials Nanoarchitectonics (MANA), National Institute for Materials Science (NIMS), 1-1 Namiki, Tsukuba 205-0044, Japan ${ }^{9}$ PRESTO, JST, 4-1-8 Honcho, Kawaguchi, Saitama 332-0012, Japan ${ }^{*}$ Corresponding Author: Toshihiro Okamoto, tokamoto@k.u-tokyo.ac.jp 


\section{Abstract}

2 Molecular assembly is a crucial factor for charge transports in organic semiconductors (OSCs), and molecularly flexible alkyl chain substitution is a key design feature for achieving desired molecular assemblies. However, the high degree of freedom of alkyl chains leads to molecular fluctuations that are detrimental to OSC performances. Stabilization of alkyl chains via intermolecular interactions in packing structures exists in biological and materials systems, and such a strategy can be harnessed in OSCs to suppress molecular fluctuations. Here, we present a robust synthetic strategy for a series of asymmetric n-type benzo[de]isoquinolino[1,8$g h$ ]quinolinetetracarboxylic diimide (BQQDI) OSCs with various alkyl chain lengths, and certain alkyl chains exhibit an unusual molecular mimicry with energetically favorable gauche conformer that shows isomorphic structures and small molecular fluctuations. Asymmetric ntype OSC with the optimum chain length exhibits satisfactory solubility, excellent electron mobility, and large-area single-crystalline thin films are fabricated for practical organic electronics.

\section{Introduction}

Molecularly flexible alkyl chains are of vital importance for controlling molecular assemblies of functional materials and biomolecules from liquid crystals ${ }^{1}$ to lipid bilayers ${ }^{2}$. In the area of printable and flexible small-molecule organic semiconductors (OSCs), which selfaggregate via intermolecular interactions, effective molecular assemblies by rational alkyl chain engineering can lead to strong intermolecular orbital overlaps ${ }^{3}$, high charge-carrier mobilities $(\mu)$, and band-like charge transports ${ }^{4-7}$. Another critical role of long alkyl chains is to control solubility and crystallinity of OSCs for solution-processability with common organic solvents and achieve large-area printable electronics ${ }^{8}$. However, one common phenomenon with alkyl chains in functional materials and biological systems is the anti-gauche isomerization at different temperatures due to the relatively small energy difference between these rotamers, ${ }^{9}$ and such a thermal disordering causes severe molecular fluctuations in molecular systems. Although these properties may be harnessed for materials applications such as stimuli sensors ${ }^{10}$, molecular fluctuations have been shown to be a detrimental factor for charge-transport properties as they disrupt intermolecular orbital overlaps ${ }^{11-16}$. Currently, our knowledge on suppressing molecular fluctuations of OSCs from a molecular design point of view has been limited, but in biological systems, certain membrane proteins show stabilization of amino acid sidechains via intermolecular hydrogen bonding interactions ${ }^{17,18}$, and similar stabilization effect of alkyl chain conformations can also be observed in host-guest materials 
1 systems ${ }^{18-20}$. On the basis of these findings, inspirations can be drawn from nature for 2 molecular design of OSCs, where motions of alkyl chains are stabilized by appropriate intermolecular interactions to achieve suppression of molecular fluctuations and such a feature is especially crucial for the molecular design of future high-performance OSCs.
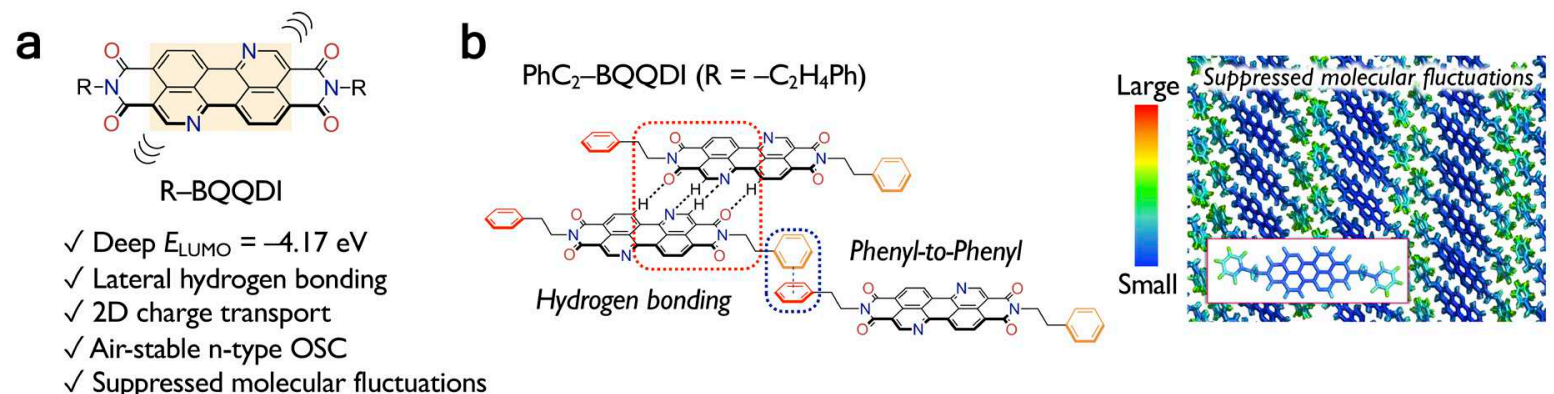

$\checkmark$ Suppressed molecular fluctuations

\section{C}

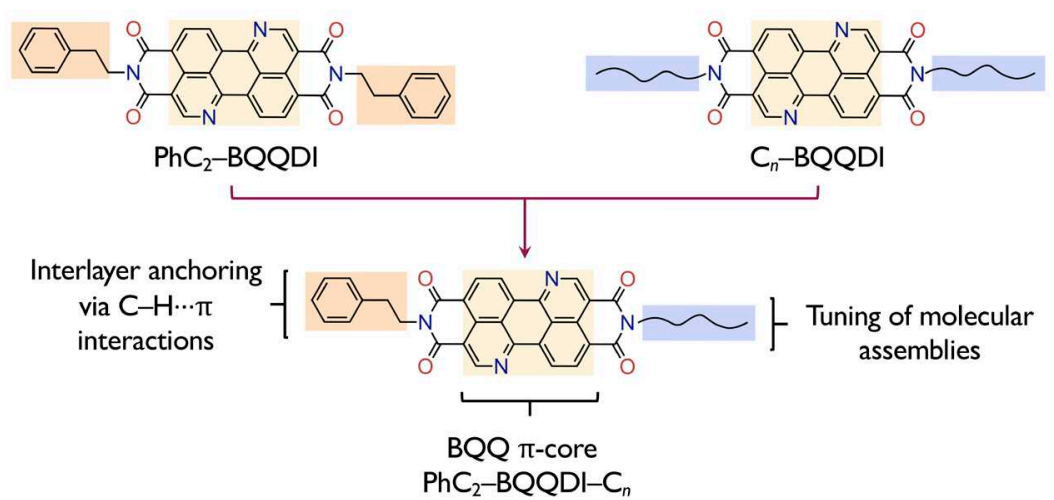

6 Fig. 1 General molecular features. a Molecular structure and features of BQQDI. b

7 Molecular assembly and fluctuations of $\mathrm{PhC}_{2}-\mathrm{BQQDI}$. $\mathbf{c}$ Molecular design of asymmetric

$8 \quad \mathrm{PhC}_{2}-\mathrm{BQQDI}-\mathrm{C}_{n}\left(C_{n}\right.$ : linear alkyl chains, $\left.n-\mathrm{C}_{n} \mathrm{H}_{2 n+1}\right)$.

Herein, we present an effective stabilization of alkyl chains with suppressed molecular fluctuations on electron-transporting n-type OSCs, which are an urgently demanded component for all-organic logic circuits $^{21-25}$ along with high-performance p-type counterparts $^{26-32}$. Recently, our group developed a benzo[de]isoquinolino[1,8$g h$ ]quinolinetetracarboxylic diimide (BQQDI) $\pi$-electron core $(\pi$-core) for high-performance n-type OSCs (Fig. 1a) ) $^{33-35}$. Though the BQQDI molecular structure bares similarity with the vastly studied perylene diimide (PDI) $\pi$-core ${ }^{36-38}$, the incorporated electronegative nitrogen atoms in BQQDI leads to a deep-lying lowest unoccupied molecular orbital (LUMO) level (Fig. 1a), which offers air-stability in n-type OSC operations without further chemical modifications. Symmetric phenethyl-substituted-BQQDI ( $\left.\mathrm{PhC}_{2}-\mathrm{BQQDI}\right)$ shows four-fold intermolecular hydrogen-bonding interactions and phenyl-to-phenyl interactions in the interlayers of the crystal structure (Fig. 1b). Molecular dynamic (MD) simulations suggest both 
intra and interlayer interactions of $\mathrm{PhC}_{2}-\mathrm{BQQDI}$ suppress molecular fluctuations in the solidstate and ensure consistent molecular orbital overlaps for undisrupted charge transport (Fig. 1b). As a result, $\mathrm{PhC}_{2}-\mathrm{BQQDI}$ exhibits an outstanding and reliable $\mu_{\mathrm{e}}$ of $3.0 \mathrm{~cm}^{2} \mathrm{~V}^{-1} \mathrm{~s}^{-1}$. However, the high-performance $\mathrm{PhC}_{2}-\mathrm{BQQDI}$ exhibits issues of low solubility and difficulties with large-area thin-film fabrications due to the lack of alkyl chains. To further explore the molecular design for high-performance solution-processed OSCs with suppressed molecular fluctuations, we envisage an asymmetric $\mathrm{PhC}_{2}-\mathrm{BQQDI}-\mathrm{C}_{n}(n=5,6$, and 7) approach (Fig. 1c), where the favorable phenethyl sidechain is preserved on one side, and the substitution of flexible alkyl chains on the other side of BQQDI may lead to fine-tuning of molecular assemblies. The lack of flexible alkyl chains in $\mathrm{PhC}_{2}-\mathrm{BQQDI}$ results in low solubility and high temperature is required for solution-processed device fabrication, but the introduction of alkyl chains in current asymmetric $\mathrm{PhC}_{2}-\mathrm{BQQDI}-\mathrm{C}_{n}$ derivatives show orders of magnitude higher solubility that improves the solution processability of high-performance n-type OSCs. We discover that $\mathrm{PhC}_{2}-\mathrm{BQQDI}-\mathrm{C}_{n}$ alkyl chains mimic the overall shape of the surrounding phenyl groups by adopting the gauche conformation that is stabilized by multiple $\mathrm{CH} \cdots \pi$ interactions that demonstrate the molecular mimicry assembly, and its alkyl chains surprisingly exhibit a similar degree of molecular fluctuations as the high-performance $\mathrm{PhC}_{2}-\mathrm{BQQDI}$ with rigid phenyl groups. In particular, the $\mathrm{PhC}_{2}-\mathrm{BQQDI}-\mathrm{C}_{5}$ derivative exhibits high n-type $\mathrm{OSC}$ performances in solution-processed OFETs, and inch-scale single-crystalline thin films are obtained for the fabrication of large-area electronics using the continuous edge-casting method $^{39,40}$ due to its high solution processability.

\section{Results}

Synthesis. Although nature synthesizes asymmetric biomolecules with marvelous efficiencies ${ }^{41}$, it is a challenge for synthetic chemists to prepare asymmetric compounds due to poor selectivity and low yields ${ }^{42}$. In the case of n-type OSCs, several studies on the synthesis of asymmetric PDI have been reported ${ }^{43-45}$. The commonly employed strategy involves sequential imidizations that results in the desired monoimidized product, along with unreacted and difunctionalized species, which are attributed to the high reactivity of primary $\mathrm{R}-\mathrm{NH}_{2}$. Owing to the relatively low solubility of PDI, purification of the desired asymmetric compound can be difficult, which leads to poor yields and low purity. Thus, we speculate that similar synthetic strategies for asymmetric PDI may not be applicable to the less-soluble BQQDI, and a more rational and selective method is developed to prepare asymmetric BQQDI. We lower the reactivity of the phenethylamine by functionalizing it with the $p$-methoxybenzyl (PMB) 
1 group (Fig. 2), which is a heat-stable protecting group that can endure imidization reactions at elevated temperatures and eventually be removed by acid $^{46}$.

$\mathrm{PhC}_{2}-\mathrm{NH}_{2}$ PMB Protection

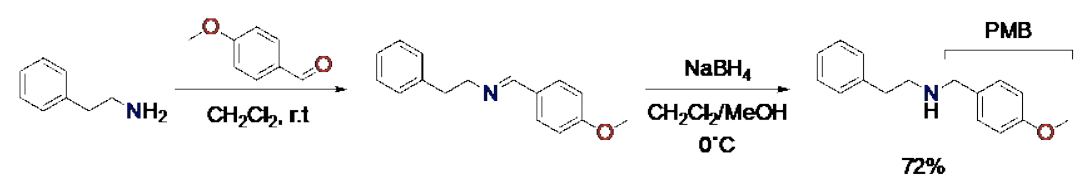

$\mathrm{PhC}_{2}-\mathrm{BQQDI}-\mathrm{C}_{\mathrm{n}}$ Synthesis

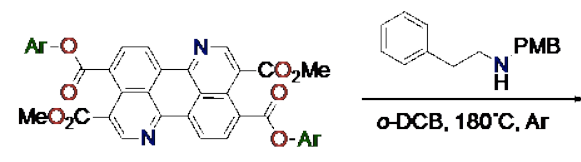

1

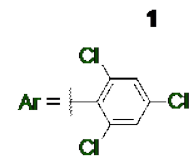

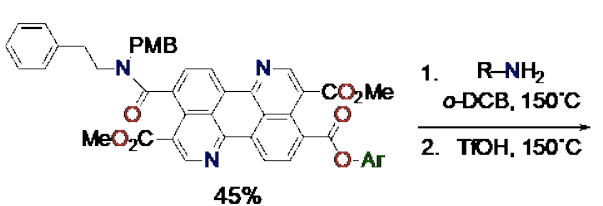

2

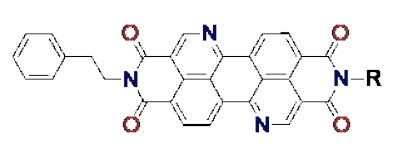

$\mathrm{PhC}_{2}$ BQQDI-C

$\mathrm{PhC}_{2}$ BQQDI-C $\mathrm{C}_{5}, 91 \%$

$\mathrm{PhC}_{2}$ BQQDI- $\mathrm{C}_{6,} 90 \%$

$\mathrm{PhC}_{2}-\mathrm{BOQDI}-\mathrm{C}_{7}, 92 \%$

Fig. 2 Synthesis of $\mathbf{P h C}_{2}-\mathbf{B Q Q D I}-\mathbf{C}_{n}$. Preparation of PMB-protected phenethylamine, and synthesis of $\mathrm{PhC}_{2}-\mathrm{BQQDI}-\mathrm{C}_{n}(n=5,6$, and 7).

Here, we began our synthesis from the previously reported trichlorophenyl formatecontaining compound 1 (Fig. 2) ${ }^{47}$, as the versatile electron-deficient formate can be readily displaced by alkylamines and purified by column chromatography. The PMB-protected amine was then reacted with compound $\mathbf{1}$ in refluxed $o$-dichlorobenzene (o-DCB) for 40 min to give intermediate 2 in $45 \%$ yield. Although the first reaction generated the desired and difunctionalized products, as well as unreacted compound $\mathbf{1}$ indicated by high-performance liquid chromatography (HPLC), compound 2 was readily isolated by column chromatography. From the key precursor $\mathbf{2}$, we carried out a highly selective one-pot synthesis to furnish a series of $\mathrm{PhC}_{2}-\mathrm{BQQDI}-\mathrm{C}_{n}(n=5,6$, and 7) from intermediate 2 (Fig. 2), as PMB removal and ringclosing steps can be simultaneously facilitated by $\mathrm{TfOH}$, and the one-pot synthesis resulted in excellent yields of $90-92 \%$. One drawback for the high-performance $\mathrm{PhC}_{2}-\mathrm{BQQDI}$ is the low solubility in common organic solvents due to the lack of flexible alkyl chains, and high temperature $\left(>150{ }^{\circ} \mathrm{C}\right)$ is required for large-area device fabrications. Current asymmetric $\mathrm{PhC}_{2}-$ BQQDI- $\mathrm{C}_{n}$ show more than one order of magnitude higher solubility in $o$-DCB than $\mathrm{PhC}_{2}-$ BQQDI (Supplementary Table 1), which indicates high solution-processability.

Fundamental properties. The thermal stability of $\mathrm{PhC}_{2}-\mathrm{BQQDI}-\mathrm{C}_{n}$ compounds was evaluated by thermalgravimetric-differential thermal analysis (TG-DTA), and the crystal phase stability/transition was measured by differential scanning calorimetry (DSC). All $\mathrm{PhC}_{2}-$ 
1 BQQDI- $\mathrm{C}_{n}$ derivatives showed excellent thermal stability with 5\% weight loss temperatures 2 ( $\left.T_{95}\right)$ and decomposition temperatures above $370{ }^{\circ} \mathrm{C}$ and $380{ }^{\circ} \mathrm{C}$, respectively (Supplementary

3 Fig. 8). DSC measurements indicated no apparent phase transitions of $\mathrm{PhC}_{2}-\mathrm{BQQDI}-\mathrm{C}_{n}$ up to $250^{\circ} \mathrm{C}$ (Supplementary Fig. 9). All $\mathrm{PhC}_{2}-\mathrm{BQQDI}-\mathrm{C}_{n}$ derivatives exhibited completely reversible reduction waves in cyclic voltammetry $(\mathrm{CV})$ measurements (Supplementary Fig. 10). The length of alkyl chains did not impose noticeable effects in electrochemical properties, as all derivatives showed first half-width reduction waves at $-0.68 \mathrm{~V}$ that corresponded to the lowest unoccupied molecular orbital (LUMO) $E_{\mathrm{LUMO}}=-4.12 \mathrm{eV}$, and the second reduction waves at $-1.0 \mathrm{~V}$ appeared to be reversible and electrochemically stable. The electrochemical properties of $\mathrm{PhC}_{2}-\mathrm{BQQDI}-\mathrm{C}_{n}$ indicate a deep-lying LUMO level that is suitable for air-stable n-channel OFET operations ${ }^{48}$.

Molecular assemblies and charge transport. We examined the plate-like single crystals of $\mathrm{PhC}_{2}-\mathrm{BQQDI}-\mathrm{C}_{n}$ grown by means of slow cooling in solutions (Supplementary Table 2), and all derivatives crystallized in the monoclinic system. Within each crystallographic layer, $\mathrm{PhC}_{2}-$ BQQDI- $\mathrm{C}_{n}$ derivatives form the $2 \mathrm{D}$ brickwork packing motif with vertical $\pi-\pi$ stacking and lateral hydrogen-bonding interactions (Fig. 3a). To our surprise, the asymmetric molecules did not form the expected phenyl-to-phenyl interlayer interactions shown in $\mathrm{PhC}_{2}-\mathrm{BQQDI}$, instead, $\mathrm{PhC}_{2}-\mathrm{BQQDI}-\mathrm{C}_{n}$ derivatives demonstrate the layer-by-layer molecular assembly where the alkyl chains interact with phenyl groups in the adjacent layer (Fig. 3a). An intriguing finding of $\mathrm{PhC}_{2}-\mathrm{BQQDI}-\mathrm{C}_{n}$ derivatives is their molecular mimicry assemblies by the alkyl chain conformations. Instead of the expected linear anti conformation, $\mathrm{PhC}_{2}-\mathrm{BQQDI}-\mathrm{C}_{5}$ shows a gauche conformation at the $\mathrm{C} 2-\mathrm{C} 3$ bond with a torsion angle of $-71.4^{\circ}$, and $\mathrm{PhC}_{2}-$ BQQDI- $\mathrm{C}_{6}$ exhibits gauche conformations at $\mathrm{C} 2-\mathrm{C} 3$, and $\mathrm{C} 4-\mathrm{C} 5$ bonds with torsion angles of $69.3^{\circ}$ and $-4.8^{\circ}$, respectively. By further extending the alkyl chain to $n=7$, such a molecular mimicry is still retained, with torsion angles of $-64.1^{\circ}$ and $101.1^{\circ}$ (Fig. 3a). Though, the long $\mathrm{C}_{7}$ alkyl chain with the gauche conformation likely causes severe thermal disordering compared to other two derivatives. We then performed a torsion angle energy scan at $\mathrm{C} 2-\mathrm{C} 3$ of $\mathrm{PhC}_{2}-\mathrm{BQQDI}-\mathrm{C}_{5}$ (Fig. 3b), and the potential energy profile of the single molecule showed a textbook-like profile, where the most energetically favorable rotamer is the anti form, though the gauche conformation is merely $0.86 \mathrm{kcal} \mathrm{mol}^{-1}$ higher than that of the anti conformation. However, in the crystal structure of $\mathrm{PhC}_{2}-\mathrm{BQQDI}-\mathrm{C}_{5}$, each alkyl chain is surrounded by four phenyl groups, and when this "aromatic pocket" is taken into consideration in the DFT calculation, the gauche rotamer becomes the most stable form and the anti rotamer is now 25 
$1 \mathrm{kcal} \mathrm{mol}^{-1}$ higher in energy than the gauche due to steric hinderance (Fig. 3c). The stabilization 2 of the molecular mimicry is arguably attributed to the multiple $\mathrm{CH} \cdots \pi$ interactions within the 3 aromatic pocket, and the large energy barrier between the anti and gauche rotamers would 4 make conformational isomerization unlikely at room temperature, and usual alkyl chain 5 molecular fluctuations may be suppressed. The powders of $\mathrm{PhC}_{2}-\mathrm{BQQDI}-\mathrm{C}_{5}$ are further 6 subjected to temperature-variant powder X-ray diffractions (PXRD) at SPring-8 RIKEN

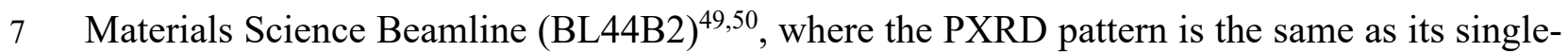
8 crystal structure, and consistent diffraction patterns are observed up to $200{ }^{\circ} \mathrm{C}$, indicating that 9 the intriguing molecular assembly is persistent (Supplementary Fig. 11). The current findings 10 of the molecular mimicry of $\mathrm{PhC}_{2}-\mathrm{BQQDI}-\mathrm{C}_{n}$ is unique among OSCs including the 11 asymmetric benzothieno-[3,2-b][1] benzothiophene (Ph-BTBT- $\mathrm{C}_{n}$ ) derivatives reported by 12 Hasegawa and Hanna groups ${ }^{51,52}$, where alkyl substituents are found to adopt the expected 13 linear anti conformations. 


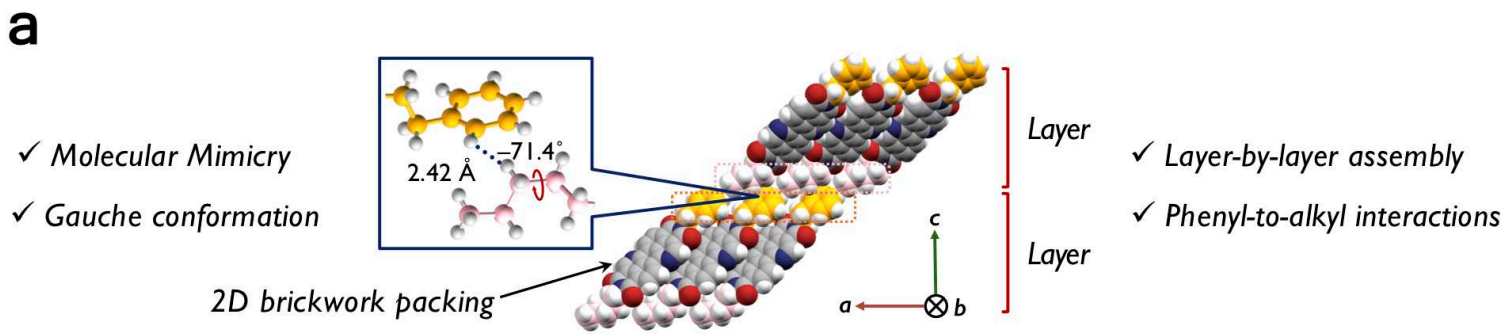

$\mathrm{PhC}_{2}-\mathrm{BQQDI}-\mathrm{C}_{5}$

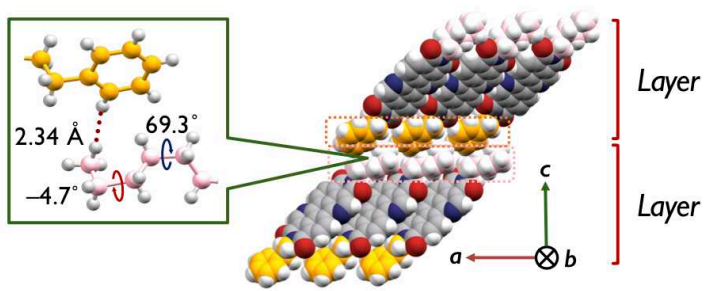

$\mathrm{PhC}_{2}-\mathrm{BQQDI}-\mathrm{C}_{6}$

b

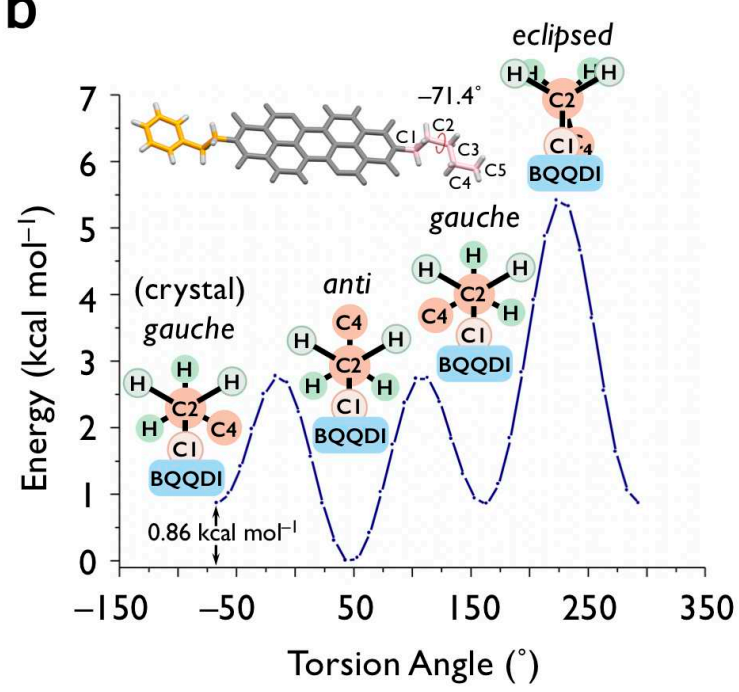

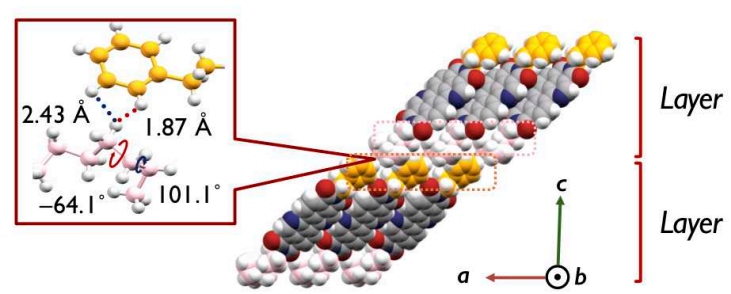

$\mathrm{PhC}_{2}-\mathrm{BQQDI}-\mathrm{C}_{7}$

C

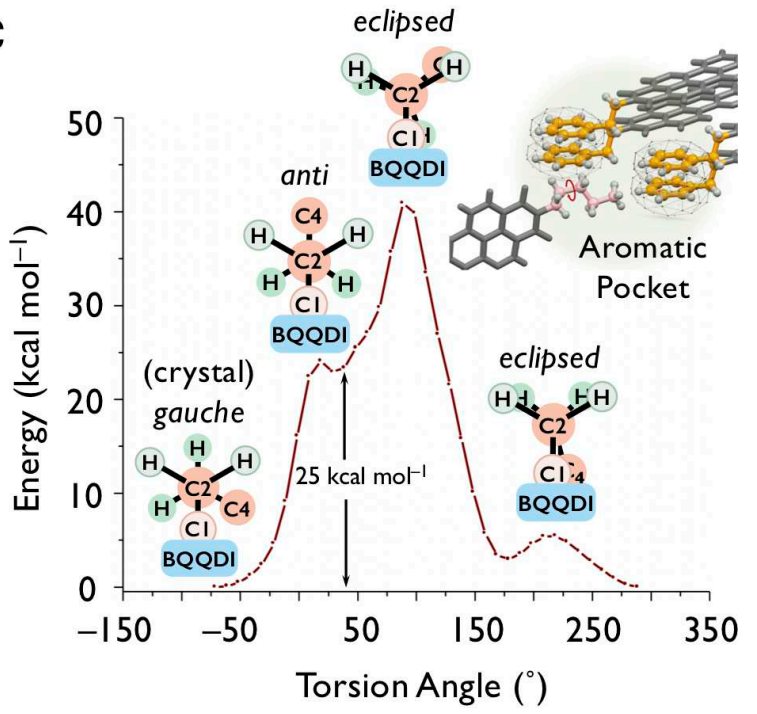

2 Fig. 3 Molecular assemblies and alkyl chain conformations. a Packing structures and

3 interlayer interactions of $\mathrm{PhC}_{2}-\mathrm{BQQDI}-\mathrm{C}_{n}$. b-c Torsion angle energy scans $(\mathrm{C} 2-\mathrm{C} 3$, starting

4 from $-71.4^{\circ}$ ) of $\mathrm{PhC}_{2}-\mathrm{BQQDI}-\mathrm{C}_{5}$ monomer and pentamer (structures from the single crystal)

5 at the B3LYP/6-31G+(d) level of theory.

6 Besides the intriguing interlayer assemblies, we investigated the charge-transport 7 capabilities of $\mathrm{PhC}_{2}-\mathrm{BQQDI}-\mathrm{C}_{n}$. Multi-fold hydrogen-bonding interactions with force 8 constants in the range of -6.72 to $-7.45 \mathrm{~kJ} \mathrm{~mol}^{-1}$ were suggested by our calculations between 9 the BQQDI $\pi$-cores in $\mathrm{PhC}_{2}-\mathrm{BQQDI}-\mathrm{C}_{n}$ crystals, and four other vertical $\pi$ - $\pi$ interactions are present in the $2 \mathrm{D}$ brickwork packing motif. To quantify the degree of LUMO overlap within the brickwork motif of $\mathrm{PhC}_{2}-\mathrm{BQQDI}-\mathrm{C}_{n}$, the $t$ values $\left(t_{1,4}, t_{2,5}, t_{3,6}\right)$ were calculated at the PBEPBE/6-31G(d) level of theory (Fig. 4a). The vertical $\pi-\pi$ interactions of $\mathrm{PhC}_{2}-\mathrm{BQQDI}-\mathrm{C}_{n}$ 
1 exhibit large $t_{1,4}$ and $t_{2,5}$ values with $t_{2,5}$ values being larger than those of $t_{1,4}$, which suggests

2 slightly anisotropic charge-transport properties. The hydrogen-bonding interactions in the 3 transverse direction also result in effective LUMO overlaps with positive $t 3,6$ values ranging 4 from +17.3 to $+18.1 \mathrm{meV}$. With the tight-binding approximation, effective mass for electron 5 carriers $\left(m^{*}\right)$ of $\mathrm{PhC}_{2}-\mathrm{BQQDI}-\mathrm{C}_{n}$ are estimated from the bottom edge of their LUMO band 6 dispersions, and by plotting the inversed $m^{*}$ with respect to the crystal axes, the anisotropic charge transport of $\mathrm{PhC}_{2}-\mathrm{BQQDI}-\mathrm{C}_{n}$ derivatives is clearly visualized by the peanut-like shapes (Fig. $4 \mathrm{~b}-\mathrm{c}$ ). Nevertheless, the minimum $m^{*}$ of $\mathrm{PhC}_{2}-\mathrm{BQQDI}-\mathrm{C}_{n}$ are estimated to be $1.4-1.5$, which are promising for achieving high $\mu_{\mathrm{e}}$ in OFETs.

a 2D brickwork packing motif

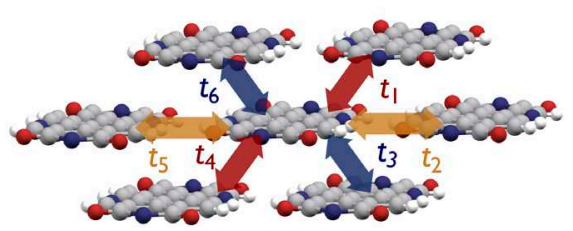

\begin{tabular}{l|c|c|c} 
& $t_{1}, t_{4}$ & $t_{3}, t_{6}$ & $t_{2}, t_{5}$ \\
\hline $\mathrm{PhC}_{2}-\mathrm{BQQDI}-\mathrm{C}_{5}$ & $+53.2 \mathrm{meV}$ & $+81.1 \mathrm{meV}$ & $+18.1 \mathrm{meV}$ \\
\hline $\mathrm{PhC}_{2}-\mathrm{BQQDI}-\mathrm{C}_{6}$ & $+55.4 \mathrm{meV}$ & $+83.8 \mathrm{meV}$ & $+17.3 \mathrm{meV}$ \\
\hline $\mathrm{PhC}_{2}-\mathrm{BQQDI}-\mathrm{C}_{7}$ & $+54.7 \mathrm{meV}$ & $+85.6 \mathrm{meV}$ & $+17.9 \mathrm{meV}$
\end{tabular}

b

\section{C}
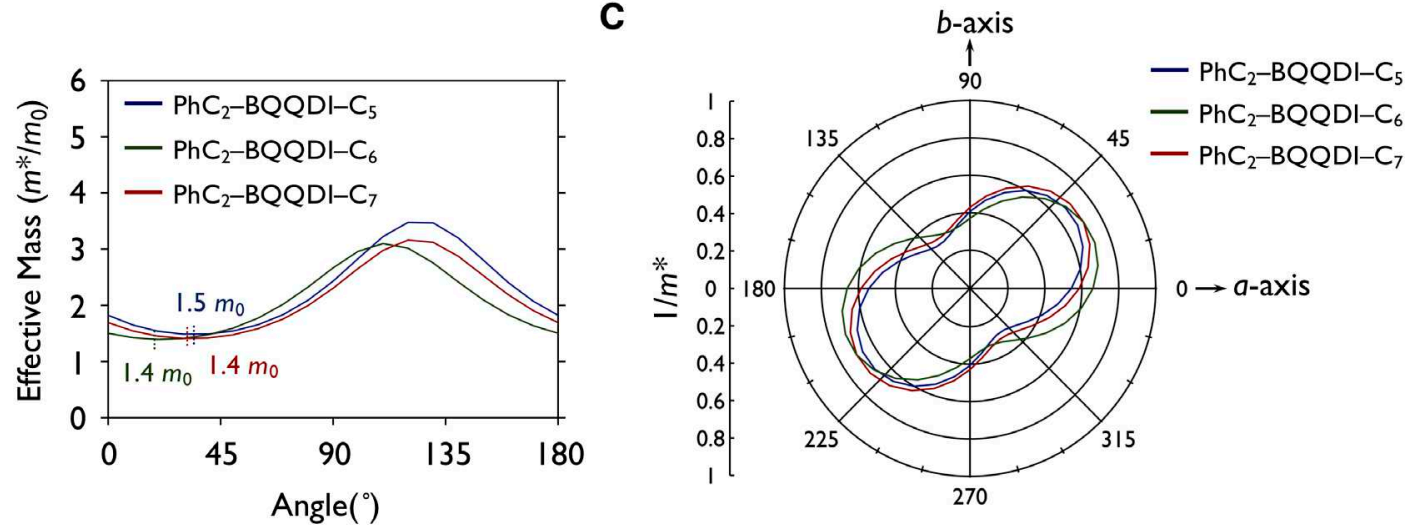

Fig. 4 Charge-transport capability of $\mathbf{P h C}_{2}-\mathbf{B Q Q D I}-\mathbf{C}_{\boldsymbol{n}}$. a Transfer integral $(t)$ in the 2D brickwork packing motif calculated at the PBEPBE/6-31G(d) level of theory. b-c Effective mass and angle-dependent inversed effective mass (relative to crystallography axes) by the tight-binding approximation, respectively.

Molecular fluctuations. The detrimental effect of molecular fluctuations or dynamic disorder of OSCs on charge transport has been studied in recent years ${ }^{11-15}$, here, we intend to explore the interlayer interactions and molecular fluctuations of $\mathrm{PhC}_{2}-\mathrm{BQQDI}-\mathrm{C}_{n}$ using $\mathrm{MD}$ simulations, with constant number of molecules $(\mathrm{N})$, temperature $(\mathrm{T})$ and pressure $(\mathrm{P})$ (isothermal-isobaric, NTP ensemble). In the previous study, we have demonstrated small molecular fluctuations of $\mathrm{PhC}_{2}-\mathrm{BQQDI}$ (Fig. 1b) attributed by strong intralayer $\pi$-core and 
interlayer phenyl-to-phenyl interactions. Surprisingly, despite having the molecularly flexible alkyl group, the interlayer chains of asymmetric $\mathrm{PhC}_{2}-\mathrm{BQQDI}-\mathrm{C}_{5}$ also show similarly small degree of molecular fluctuations (small B-factors) as $\mathrm{PhC}_{2}$-BQQDI (Fig. 5a), which is possibly due to the stabilization effect on the molecular mimicry by the "aromatic pocket" (Fig. 3d), and the $\pi$-core of $\mathrm{PhC}_{2}-\mathrm{BQQDI}-\mathrm{C}_{5}$ also shows small degree of fluctuations. Based on this result, we argue that the alkyl chain $\mathrm{PhC}_{2}-\mathrm{BQQDI}-\mathrm{C}_{5}$ does not behave as an ordinary flexible alkyl chain, but it rather mimics a structurally rigid phenyl group, which leads to suppressed molecular fluctuations. Similarly, $\mathrm{PhC}_{2}-\mathrm{BQQDI}-\mathrm{C}_{6}$ also exhibits small amplitude of molecular fluctuations in the $\pi$-cores, but the alkyl chains show noticeably large B-factors and destabilization of the molecular mimicry conformation (Fig. 5b). The thermally disordered $\mathrm{PhC}_{2}-\mathrm{BQQDI}-\mathrm{C}_{7}$ expectedly demonstrates large degree of molecular fluctuations in the alkyl chains and the molecular mimicry in the single-crystal structure is no longer retained during the MD simulations (Fig. 5c). In addition, the $\pi$-cores of $\mathrm{PhC}_{2}-\mathrm{BQQDI}-\mathrm{C}_{7}$ show larger amplitudes of molecular fluctuations which could potentially affect the charge-transport capability.

a

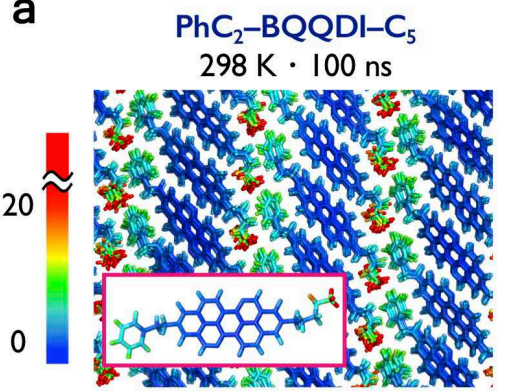

d

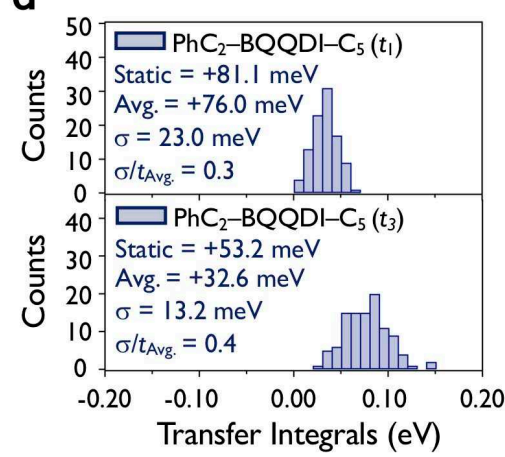

b $\mathrm{PhC}_{2}-\mathrm{BQQDI}-\mathrm{C}_{6}$ $298 \mathrm{~K} \cdot 100 \mathrm{~ns}$

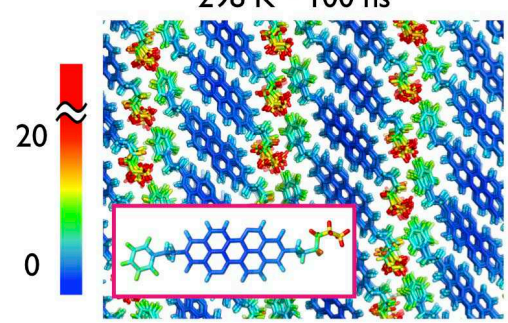

e

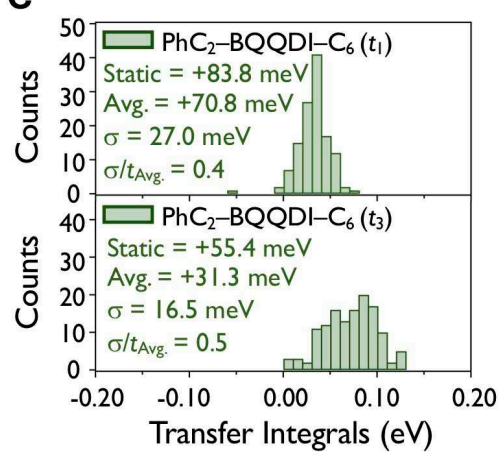

C $\mathrm{PhC}_{2}-\mathrm{BQQDI}-\mathrm{C}_{7}$ $293 \mathrm{~K} \cdot 100 \mathrm{~ns}$

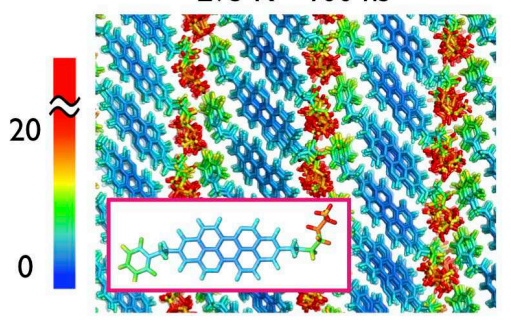

f

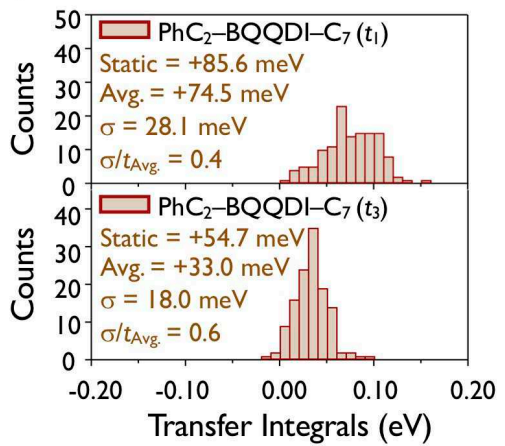

Fig. 5 Molecular fluctuations by MD simulations. a-c Color-coded B-factor $\left(\AA^{2} \mathrm{~s}^{-1}\right)$ distribution of $\mathrm{PhC}_{2}-\mathrm{BQQDI}-\mathrm{C}_{n}(n=5,6$, and 7) obtained from the trajectories during the last $10 \mathrm{~ns}$ of a $100 \mathrm{~ns}$ MD simulations in the NTP ensemble and variant transfer integrals $\left(t_{1}\right.$ and $\left.t_{3}\right)$ at $100 \mathrm{~ns}$ of the MD simulations. d-f Variant $t$ value distributions and standard deviations $(\sigma)$ revealing the magnitude of the dynamic fluctuations. 
We calculated the variant $t$ values to understand the effect of molecular fluctuations on charge transport in the $\pi-\pi$ stacking directions of $\mathrm{PhC}_{2}-\mathrm{BQQDI}-\mathrm{C}_{n}$ based on the MD simulations. $\mathrm{PhC}_{2}-\mathrm{BQQDI}-\mathrm{C}_{5}$ exhibits the smallest standard deviations $(\sigma)$ of $23.0 \mathrm{meV}$ and $13.2 \mathrm{meV}$ in the $t_{1}$ and $t_{3}$ directions, respectively (Fig. $5 \mathrm{~d}$ ), which suggests that the chargetransport capability of $\mathrm{PhC}_{2}-\mathrm{BQQDI}-\mathrm{C}_{5}$ does not appear to be affected by molecular fluctuations. The $\sigma$ values of $\mathrm{PhC}_{2}-\mathrm{BQQDI}-\mathrm{C}_{5}$ are in fact lower than the high-performance $\mathrm{PhC}_{2}-\mathrm{BQQDI}(13.9 \mathrm{meV} \text { and } 24.2 \mathrm{meV})^{33}$ in their respective directions, which further demonstrates the effectiveness of molecular mimicry in suppressing molecular fluctuations. On the other hand, $\mathrm{PhC}_{2}-\mathrm{BQQDI}-\mathrm{C}_{n}(n=6$ and 7) result in large $\sigma$ of $t$ values compared to $\mathrm{PhC}_{2}-\mathrm{BQQDI}-\mathrm{C}_{5}$ due to their molecular fluctuations (Fig. 5e-f), which suggest potentially compromised charge-transport capabilities. In addition, it has been reported that the ratio of $\sigma$ and averaged $t$ values $\left(\sigma / t_{\text {Avg. }}\right)$ quantifies the effect of molecular fluctuations on charge transport ${ }^{55}$, and $\mathrm{PhC}_{2}-\mathrm{BQQDI}-\mathrm{C}_{5}$ shows the smallest $\sigma / t_{\text {Avg. }}$ in both $t_{1}$ and $t_{3}$ directions $(0.30$ and 0.40) (Fig. 5d) among current derivatives, indicating its promising OSC performances.

Device performances. To evaluate n-type OSC performances of $\mathrm{PhC}_{2}-\mathrm{BQQDI}-\mathrm{C}_{n}(n=5,6$, and 7) under ambient conditions, we fabricated bottom-gate/top-contact single-crystalline thinfilm OFETs via the edge-casting method ${ }^{53}$. We have confirmed that the single-crystalline thin films of all three $\mathrm{PhC}_{2}-\mathrm{BQQDI}-\mathrm{C}_{n}$ are consistent with their bulk single crystal structures to correlate their estimated charge-transport capabilities and device performances (Supplementary Fig. 12-14). $\mathrm{PhC}_{2}-\mathrm{BQQDI}-\mathrm{C}_{5}$ with the molecular mimicry demonstrates excellent single-crystalline thin films (Fig. 6a) and the best OFET behavior demonstrating textbook-like transfer and output characteristics with a high $\mu_{\mathrm{e}}$ of $1.4 \mathrm{~cm}^{2} \mathrm{~V}^{-1} \mathrm{~s}^{-1}$ and a reliability factor $(r)^{54}$ of 0.86 , which leads to an effective $\mu_{\mathrm{e}}$ of $1.0 \mathrm{~cm}^{2} \mathrm{~V}^{-1} \mathrm{~s}^{-1}$ (Fig. $6 \mathrm{~b}-\mathrm{c}$ ). The highest $\mu_{\mathrm{e}}$ of $1.4 \mathrm{~cm}^{2} \mathrm{~V}^{-1} \mathrm{~s}^{-1}$ can be obtained for $\mathrm{PhC}_{2}-\mathrm{BQQDI}-\mathrm{C}_{5}$, and it shows an averaged $\mu_{\mathrm{e}}$ of $1.2 \mathrm{~cm}^{2} \mathrm{~V}^{-1} \mathrm{~s}^{-1}$ over seven devices using the same fabrication method (Supplementary Fig. 15), which further demonstrates the reliability of its OFET performance. $\mathrm{PhC}_{2}-\mathrm{BQQDI}-$ $\mathrm{C}_{6}$ with the similar charge-transport capability and exhibits a similar $\mu_{\mathrm{e}}$ of $1.2 \mathrm{~cm}^{2} \mathrm{~V}^{-1} \mathrm{~s}^{-1}$, though it displays a non-ideal transfer curve with a low $r$ of 0.28 and an effective $\mu_{\mathrm{e}}$ of 0.33 $\mathrm{cm}^{2} \mathrm{~V}^{-1} \mathrm{~s}^{-1}$ (Supplementary Fig. 16a). Similarly, $\mathrm{PhC}_{2}-\mathrm{BQQDI}-\mathrm{C}_{7}$ demonstrates nonlinearity in its transfer characteristic, its highest $\mu_{\mathrm{e}}$ of $1.0 \mathrm{~cm}^{2} \mathrm{~V}^{-1} \mathrm{~s}^{-1}$ is accompanied by a low $r$ of 0.36 and an effective $\mu_{\mathrm{e}}$ of $0.36 \mathrm{~cm}^{2} \mathrm{~V}^{-1} \mathrm{~s}^{-1}$ (Supplementary Fig. 16b). The device performances of $\mathrm{PhC}_{2}-\mathrm{BQQDI}-\mathrm{C}_{n}$ herein presents a curious case since all three derivatives demonstrate extremely similar $t$ and $m^{*}$ values but completely different effective $\mu_{\mathrm{e}}$. However, based on our 
1 MD calculations, we observe that $\mathrm{PhC}_{2}-\mathrm{BQQDI}-\mathrm{C}_{5}$ exhibits the smallest molecular 2 fluctuations and variations in $t$ values, due to the stability of its molecular mimicry 3 conformation. While the other two $\mathrm{PhC}_{2}-\mathrm{BQQDI}-\mathrm{C}_{n}$ derivatives ( $n=6$ and 7) clearly display 4 large molecular fluctuations and affected charge-transport capabilities compared to $\mathrm{PhC}_{2}-$ 5 BQQDI-C5, which possibly affected their thin-film crystallinity and result in lower effective $6 \quad \mu_{\mathrm{e}}($ Supplementary Fig 17).

a

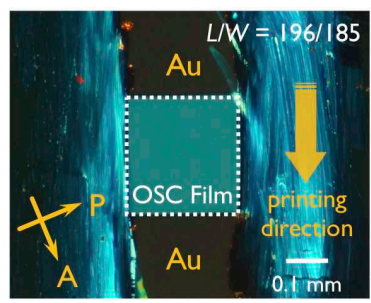

b

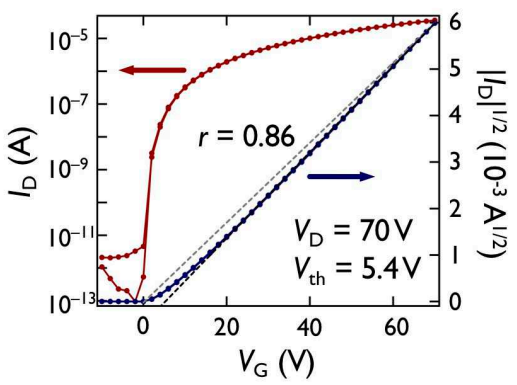

C
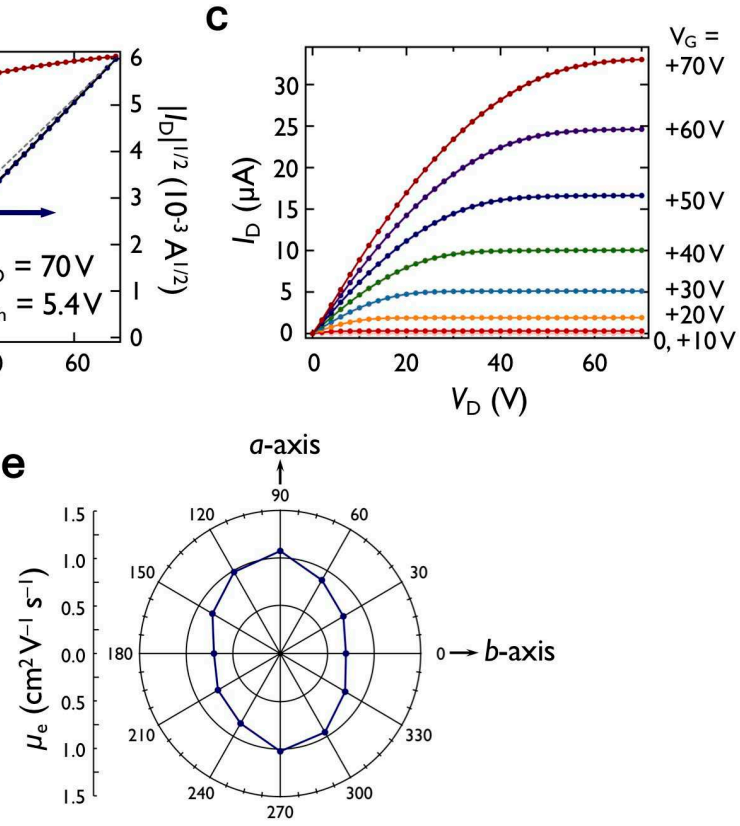

d

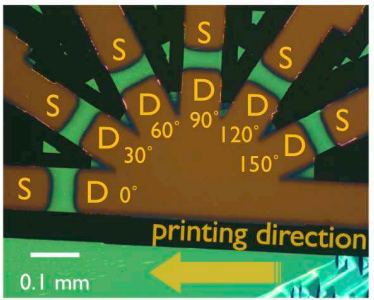

Fig. 6 OFET performances of $\mathrm{PhC}_{2}-\mathrm{BQQDI}-\mathrm{C}_{5}$. a-c Polarized microscopic image of single-crystalline thin-film OFET, transfer (black and gray dashed lines represent the fit to $\left|I_{\mathrm{D}}\right|^{1 / 2}$ and the slope of an electrically ideal $\mathrm{OFET}^{54}$, respectively) and output characteristics evaluated under ambient conditions. d-e Fan-shaped OFETs on the inch-scale singlecrystalline thin film with channels in every $30^{\circ}$ relative to the printing direction $(L=\sim 40 \mu \mathrm{m}$, $W=\sim 90 \mu \mathrm{m})$, and the resulting azimuthal $\mu$ e.

In light of the excellent OFET performance of $\mathrm{PhC}_{2}-\mathrm{BQQDI}-\mathrm{C}_{5}$, we successfully fabricated its centimeter-scale single-crystalline thin films using our recently reported continuous edgecasting solution-processed method ${ }^{39,40}$ (Supplementary Fig. 18), the excellent processability is attributed to its high crystallinity and suitable solubility, which also shows potentials for applicable electronics. We examined the device performance as well as anisotropic $\mu_{\mathrm{e}}$ of the large-area single-crystalline thin film of $\mathrm{PhC}_{2}-\mathrm{BQQDI}-\mathrm{C}_{5}$ (Fig. 6d). For the preliminary devices of $\mathrm{PhC}_{2}-\mathrm{BQQDI}-\mathrm{C}_{5}$, we constructed the OFET channel along its crystal growth direction ( $b$-axis). However, both our effective mass and anisotropic $\mu_{\mathrm{e}}$ of the large-area singlecrystalline device suggest that the $b$-axis/printing direction is not the best charge-transport 
direction. From the plotted azimuthal $\mu_{\mathrm{e}}$ (Fig. 6e), it is apparent that the $a$-axis direction gives the best charge transport, and the experimental result herein is approximately consistent with our angular-dependent inversed effective mass calculations. We anticipate that with optimized device engineering condition, $\mathrm{PhC}_{2}-\mathrm{BQQDI}-\mathrm{C}_{5}$ has the potential to show further improved $\mu_{\mathrm{e}}$ with the appropriate OFET channel direction.

\section{Discussion}

In summary, we have developed an effective and efficient synthetic strategy for asymmetric $\mathrm{PhC}_{2}-\mathrm{BQQDI}-\mathrm{C}_{n}(n=5,6$, and 7$)$ compounds. The intriguing molecular mimicry of alkyl chains in the single-crystal structure of $\mathrm{PhC}_{2}-\mathrm{BQQDI}-\mathrm{C}_{5}$ with the gauche conformations have shown to be energetically favorable and persistent at elevated temperatures attributed to the $\mathrm{CH}^{\cdots} \cdots \pi$ stabilization from the neighboring phenyl groups. Although varying the alkyl chain length did not appear to impose a pronounce effect on the intralayer charge transport of $\mathrm{PhC}_{2}-$ BQQDI- $\mathrm{C}_{n}$, we noticed a dramatic difference in molecular fluctuations from these derivatives that may have distinct consequences in their charge-transport capabilities. The alkyl chains of $\mathrm{PhC}_{2}-\mathrm{BQQDI}-\mathrm{C}_{5}$ are stabilized by the "aromatic pocket" and mimic the behavior of rigid phenyl groups that results in small degree of molecular fluctuations. From the results of variant $t$ calculations, $\mathrm{PhC}_{2}-\mathrm{BQQDI}-\mathrm{C}_{5}$ show the smallest $\sigma$ of $t$ values, which demonstrates the effectiveness of such a molecular mimicry in suppressing molecular fluctuations. $\mathrm{PhC}_{2}-$ BQQDI- $\mathrm{C}_{5}$ shows the best OFET characteristics among current asymmetric $\mathrm{PhC}_{2}-\mathrm{BQQDI}-\mathrm{C}_{n}$ OSCs with the highest $\mu_{\mathrm{e}}$ of $1.4 \mathrm{~cm}^{2} \mathrm{~V}^{-1} \mathrm{~s}^{-1}$, and an excellent averaged $\mu_{\mathrm{e}}$ of $1.2 \mathrm{~cm}^{2} \mathrm{~V}^{-1} \mathrm{~s}^{-1}$ is obtained over seven devices. In addition, we demonstrate that $\mathrm{PhC}_{2}-\mathrm{BQQDI}-\mathrm{C}_{5}$ possesses suitable solubility and high crystalline thin-film quality for large-area device fabrication that is promising for the development of future printable organic electronics.

\section{Methods}

Materials and General Characterization Methods. Reagents and anhydrous solvents were purchased from Tokyo Chemical Industry Co., Ltd and Kanto Chemicals, respectively, and odichlorobenzene was purified by the solvent purification system prior to use. All reactions were carried out under an atmosphere of argon. Analytical thin-layer chromatography (TLC) was performed on glass plates with silica gel containing fluorescent indicator (Merck TLC Silica gel 60 F254, 1 mm). Column chromatography was performed on Kanto silica gel 60. All HPLC spectra were recorded on a column by Phenomenex (Kinetex 5u C18 100A, New column $150 \times 4.6 \mathrm{~mm}$ ) with the mixture of solvent of THF: $\mathrm{H}_{2} \mathrm{O}=6.2: 3.8$, and the flow rate was 1.0 
$1 \mathrm{~mL} \mathrm{~min}^{-1} \cdot{ }^{13} \mathrm{C}$ NMR of compound 3 was recorded on an AVANCE $700 \mathrm{III}$, and all other NMR spectra were recorded on JEOL ECS400 spectrometer. Chemical shifts were reported in parts per million (ppm, d scale) from residual protons in the deuterated solvent for ${ }^{1} \mathrm{H}$ NMR (5.93 ppm for 1,1,2,2-tetrachloroethane- $d_{2}$ (TCE- $\left.d_{2}\right)$ and 7.26 ppm for chloroform- $\left.d\left(\mathrm{CDCl}_{3}\right)\right)$ and ${ }^{13} \mathrm{C}$ NMR (73.78 ppm for 1,1,2,2-tetrachloroethane- $d_{2}$ (TCE- $d_{2}$ ) and $77.16 \mathrm{ppm}$ for chloroform$\left.d\left(\mathrm{CDCl}_{3}\right)\right)$. The data were presented in the following format: chemical shift, multiplicity $(\mathrm{s}=$ singlet, $\mathrm{d}=$ doublet, $\mathrm{t}=$ triplet, quint $=$ quintet, $\mathrm{m}=$ multiplet, $\mathrm{br}=$ broad, brm $=$ broad multiplet), coupling constant in Hertz (Hz), signal area integration in natural numbers.

Synthetic procedure for $N$-(4-methoxybenzyl)-phenethylamine. A flame-dried roundbottom flask was charged with anhydrous $\mathrm{CH}_{2} \mathrm{Cl}_{2}(208 \mathrm{~mL}), \mathrm{MgSO}_{4}(250 \mathrm{~g}, 2.08 \mathrm{~mol}, 10$ equiv.), phenethylamine (25.3 g, $208 \mathrm{mmol}, 1.0$ equiv.) and $p$-anisaldehyde ( $28.4 \mathrm{~g}, 208 \mathrm{mmol}$, 1.0 equiv.). The mixture was stirred at room temperature for $2 \mathrm{~h}$ and filtered via vacuum filtration and the solvent was removed in vacuo. (E)-1-(4-methoxyphenyl)- $N$ phenethylmethanimine was obtained as a yellow liquid (43.3 g) and used without any purification. Subsequently, the obtained imine (43.3 g, $181 \mathrm{mmol}, 1.0$ equiv.), $\mathrm{NaBH}_{4}(18.9 \mathrm{~g}$, 500 mmol, 2.8 equiv.), anhydrous $\mathrm{CH}_{2} \mathrm{Cl}_{2}(362 \mathrm{~mL}), \mathrm{MeOH}(362.48 \mathrm{~mL})$ were added to a round-bottom flask under argon. The mixture was stirred at $0{ }^{\circ} \mathrm{C}$ for $2 \mathrm{~h}$ and the reaction was quenched by water. The compound was extracted with $\mathrm{CH}_{2} \mathrm{Cl}_{2}$ and $2 \mathrm{M} \mathrm{HCl}(100 \mathrm{~mL})$ was added to the organic layer and the precipitates were collected via filtration. The filtrates were dissolved in water $(150 \mathrm{~mL})$ and sodium carbonate was added until the white solids disappeared, and the compound was then extracted with $\mathrm{CH}_{2} \mathrm{Cl}_{2}(50 \mathrm{~mL} \times 3)$. After $\mathrm{CH}_{2} \mathrm{Cl}_{2}$ was removed in vacuo, the title compound was obtained as a light-yellow liquid without further purification (36.1 g, 72\% yield). ${ }^{1} \mathrm{H} \mathrm{NMR}\left(400 \mathrm{MHz} \mathrm{CDCl}_{3}\right): \delta 7.31-7.19(\mathrm{~m}, 7 \mathrm{H}), 6.87-6.83$ $(\mathrm{m}, 2 \mathrm{H}), 3.77(\mathrm{~d}, J=17.6 \mathrm{~Hz}, 5 \mathrm{H}), 2.92-2.81(\mathrm{~m}, 4 \mathrm{H})$. The spectrum is in good agreement with the reported $\operatorname{data}^{56}$.

Synthetic procedure for 3,9-dimethyl 4-(2,4,6-trichlorophenyl) 10-((4methoxybenzyl)(phenethyl)carbamoyl)benzo[de]isoquinolino[1,8-gh]quinoline-3,4,9tricarboxylate (2). A flame-dried three-neck round bottom flask equipped with an Ar inlet and reflex condenser was charged with 3,9-dimethyl 10,4-bis(2,4,6trichlorophenyl)benzo[de]isoquinolino[1,8-gh]quinoline-3,4,9,10-tetracarboxylate (1) (2.45 g, $3.00 \mathrm{mmol}, 1.0$ equiv.) and anhydrous $o$-DCB $(90 \mathrm{~mL})$. After the complete dissolution of 1 at $180{ }^{\circ} \mathrm{C}$, a solution of PMB amine $(2.89 \mathrm{~g}, 12.0 \mathrm{mmol}, 4.0$ equiv. $)$ was added in one portion to the system. The reaction was carried out at $180{ }^{\circ} \mathrm{C}$ and monitored by HPLC. After the peak 
area of 2 reached the maximum value (ca. $40 \mathrm{~min}$ ), the mixture was cooled down to room temperature and the solvent was removed in vacuo. The crude product was purified by silica gel column chromatography using $\mathrm{PhMe} / \mathrm{EtOAc}$ as eluents to afford compound $\mathbf{2}$ as an orange solid. (780 mg, 45\% yield). ${ }^{1} \mathrm{H}$ NMR (400 MHz, TCE- $\left.d_{2}, 100{ }^{\circ} \mathrm{C}\right): \delta 9.23-8.84(\mathrm{~m}, 5 \mathrm{H}), 8.73-$ 7.65 (brm, 1H), 7.46(s, 2H), 7.43-6.82 (brm, 9H), 5.55-4.08 (brm, 2H), 4.08-3.93 (brm, 3H), 3.89 (s, 3H,), 3.82 (s, 3H), 3.75-3.62 (brm, 2H), 3.08-2.87 (brm, 2H). HRMS (APCl $\left.{ }^{+}-\mathrm{TOF}\right)$ : Calcd for $\mathrm{C}_{46} \mathrm{H}_{32} \mathrm{Cl}_{3} \mathrm{~N}_{3} \mathrm{O}_{8}[\mathrm{M}+\mathrm{H}]$ 860.1333. Found, 860.1325. Elemental Analysis. Calcd for $\mathrm{C}_{46} \mathrm{H}_{32} \mathrm{Cl}_{3} \mathrm{~N}_{3} \mathrm{O}_{8}$ : C 64.16; H 3.75; N 4.88. Found: C 64.02; H 3.87; N 4.90.

\section{General synthetic procedure for one-pot synthesis of $\mathrm{PhC}_{2}-\mathrm{BQQDI}-\mathrm{C}_{\boldsymbol{n}}$. A flame-dried} Schlenk tube equipped with a stir bar was charged with compound 2 (400 mg, 1.0 equiv.), alkylamine (1.5 equiv.), and anhydrous $o$-DCB $(0.05 \mathrm{M})$. The mixture was heated at $150{ }^{\circ} \mathrm{C}$ for one hour under argon and subsequently cooled to room temperature. To the dark red solution was added $\mathrm{TfOH}$ ( 2.5 equiv.) and the mixture was then stirred at $150{ }^{\circ} \mathrm{C}$ for three hours under argon. As the reaction completion was indicated by ${ }^{1} \mathrm{H}$ NMR, the mixture was added dropwise to a stirring $\mathrm{MeOH}$ solution and the dark precipitates were collected via vacuum filtration. The products were recrystallized from $o$-DCB to afford the target compounds.

Characterization of $\mathbf{P h C}_{2}-\mathbf{B Q Q D I}-\mathbf{C}_{5} .240 \mathrm{mg}, 91 \%$ yield. ${ }^{1} \mathrm{H}$ NMR (400 MHz, TCE- $d_{2}$, $\left.100{ }^{\circ} \mathrm{C}\right): \delta 9.65(\mathrm{~s}, 2 \mathrm{H}), 9.28(\mathrm{~d}, J=7.6 \mathrm{~Hz}, 2 \mathrm{H}), 8.84(\mathrm{~d}, J=8.0 \mathrm{~Hz}, 2 \mathrm{H}), 7.34-7.19(\mathrm{~m}, 5 \mathrm{H})$, $4.45(\mathrm{t}, J=7.6 \mathrm{~Hz}, 8.0 \mathrm{~Hz}, 2 \mathrm{H}), 4.20$ (t, $J=7.2 \mathrm{~Hz}, 7.2 \mathrm{~Hz}, 2 \mathrm{H}), 3.08$ (t, $J=8.0 \mathrm{~Hz}, 7.2 \mathrm{~Hz}$, 2H), 1.81 (quint, $J=8.8 \mathrm{~Hz}, 6.0 \mathrm{~Hz}, 6.8 \mathrm{~Hz}, 6.0 \mathrm{~Hz}, 2 \mathrm{H}$ ), 1.44-1.27 (m, 10H), 0.95 (t, $J=6.4$ $\mathrm{Hz}, 3 \mathrm{H}$ ). HRMS (APCI $-\mathrm{TOF}$ ): Calcd for $\mathrm{C}_{35} \mathrm{H}_{26} \mathrm{~N}_{4} \mathrm{O}_{4}[\mathrm{M}+\mathrm{H}]$ 567.1954. Found 567.1958. Elemental Analysis. Calcd for $\mathrm{C}_{35} \mathrm{H}_{26} \mathrm{~N}_{4} \mathrm{O}_{4}$ : C 74.19; H 4.63; N 9.89. Found 74.17; H 4.73; N 9.80 .

Characterization of $\mathbf{P h C}_{2}-\mathbf{B Q Q D I}-\mathbf{C}_{6} .243 \mathrm{mg}, 90 \%$ yield. ${ }^{1} \mathrm{H}$ NMR (400 MHz, TCE- $d_{2}$, $\left.100{ }^{\circ} \mathrm{C}\right): \delta 9.64(\mathrm{~s}, 2 \mathrm{H}), 9.28(\mathrm{~d}, J=7.6 \mathrm{~Hz}, 2 \mathrm{H}), 8.84(\mathrm{~d}, J=8.0 \mathrm{~Hz}, 2 \mathrm{H}), 7.34-7.19(\mathrm{~m}, 5 \mathrm{H})$, 4.45 (t, $J=7.2 \mathrm{~Hz}, 8.4 \mathrm{~Hz}, 2 \mathrm{H}), 4.20$ (t, $J=7.6 \mathrm{~Hz}, 7.2 \mathrm{~Hz}, 2 \mathrm{H}), 3.08$ (t, $J=7.2 \mathrm{~Hz}, 84 \mathrm{~Hz}$ ), 1.78 (quint, $J=8.0 \mathrm{~Hz}, 6.4 \mathrm{~Hz}, 7.2 \mathrm{~Hz}, 8.0 \mathrm{~Hz}, 2 \mathrm{H}), 1.47-1.27(\mathrm{~m}, 6 \mathrm{H}), 0.92$ (t, $J=6.4 \mathrm{~Hz}, 6.8$ $\mathrm{Hz}, 3 \mathrm{H}$ ). HRMS (APCI ${ }^{+}$-TOF): Calcd for $\mathrm{C}_{36} \mathrm{H}_{28} \mathrm{~N}_{4} \mathrm{O}_{4}[\mathrm{M}+\mathrm{H}]$ 581.2111. Found 581.2124. Elemental Analysis. Calcd for $\mathrm{C}_{36} \mathrm{H}_{28} \mathrm{~N}_{4} \mathrm{O}_{4}$ : C 74.47; H 4.86; N 9.65. Found C 74.32; H 4.96; N 9.44 .

Characterization of $\mathbf{P h C}_{2}-\mathbf{B Q Q D I}-\mathbf{C}_{7} .254 \mathrm{mg}, 92 \%$ yield. ${ }^{1} \mathrm{H}$ NMR (400 MHz, TCE- $d_{2}$, $\left.100{ }^{\circ} \mathrm{C}\right): \delta 9.64(\mathrm{~s}, 2 \mathrm{H}), 9.27(\mathrm{~d}, J=8.0 \mathrm{~Hz}, 2 \mathrm{H}), 8.84(\mathrm{~d}, J=7.6 \mathrm{~Hz}, 2 \mathrm{H}), 7.34-7.19(\mathrm{~m}, 5 \mathrm{H})$, 
$4.45(\mathrm{t}, J=7.6 \mathrm{~Hz}, 8.4 \mathrm{~Hz}, 2 \mathrm{H}), 4.20$ (t, $J=7.2 \mathrm{~Hz}, 7.6 \mathrm{~Hz}, 2 \mathrm{H}), 3.08$ (t, $J=7.6 \mathrm{~Hz}, 8 \mathrm{~Hz}, 2 \mathrm{H})$, 1.79 (quint, $J=7.6 \mathrm{~Hz}, 7.2 \mathrm{~Hz}, 7.2 \mathrm{~Hz}, 7.6 \mathrm{~Hz}, 2 \mathrm{H}), 1.43-1.32$ (m, 9H), 0.90 (t, $J=6.8 \mathrm{~Hz}, 6.8$ $\mathrm{Hz}, 3 \mathrm{H}$ ). HRMS (APCI ${ }^{+}$-TOF): Calcd for $\mathrm{C}_{37} \mathrm{H}_{30} \mathrm{~N}_{4} \mathrm{O}_{4}[\mathrm{M}+\mathrm{H}]$ 595.2345. Found 595.2348. Elemental Analysis. Calcd for $\mathrm{C}_{37} \mathrm{H}_{30} \mathrm{~N}_{4} \mathrm{O}_{4}$ : C 74.73; H 5.09; N 9.42. Found C 74.71; H 5.16; N 9.22 .

Theoretical calculations. Theoretical calculations of transfer integral and effective mass were conducted using the GAMESS package ${ }^{57}$. The Kohn-Sham eigenstates of all compounds in this work were calculated at the PBEPBE/6-31G(d) level of theory. Transfer integrals $(t)$ between LUMOs of neighboring molecules in the crystal structures were estimated by the dimer method ${ }^{3}$. To further understand the carrier transporting capabilities in the single-crystal state, their LUMO band structures $E(k)$ were calculated by the tight-binding approximation using transfer integrals. Intermolecular interaction energy between two adjacent molecules were obtained at the M06-2X/6-31++G(d,p) level of DFT with counterpoise correction for the basis set superposition error ${ }^{58}$. The calculations were performed using the Gaussian 09 program package ${ }^{59}$.

Electrochemical measurements. Cyclic voltammetry was conducted on a BAS electrochemical analyzer ALS 622D using a three-electrode cell with a glassy carbon as the working electrode, a Pt wire as the counter electrode and $0.01 \mathrm{M} \mathrm{Ag} / \mathrm{AgNO}_{3}$ (in benzonitrile containing $0.1 \mathrm{M}$ tetrabutylammonium hexafluorophosphate $\left(\mathrm{TBAPF}_{6}\right)$ ) as the reference electrode. The measurements were carried out under an argon atmosphere using a benzonitrile solution at $100{ }^{\circ} \mathrm{C}$ with a concentration of $0.25 \mathrm{mM}$, and $0.1 \mathrm{M} \mathrm{TBAPF}_{6}$ as a supporting electrolyte with a scan rate of $0.1 \mathrm{~V} \mathrm{~s}^{-1}$. The redox potentials were calibrated with ferrocene $\left(\mathrm{Fc} ; E\left(\mathrm{Fc} / \mathrm{Fc}^{+}\right)=0 \mathrm{~V}\right)$ as an internal standard. Benzonitrile was passed through a pad of aluminum oxide 60 for purification prior to use.

Thermal property measurements. Thermogravimetric-differential thermal analysis was performed on a Rigaku Thermo Plus EVO II TG 8121 at a heating rate of $1 \mathrm{~K} \mathrm{~min}^{-1}$ under a

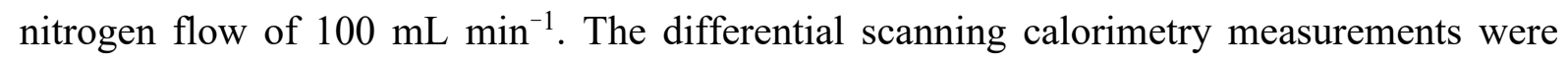
performed with a Rigaku Thermo Plus EVO II DSC 8270 at a heating rate of $5 \mathrm{~K} \mathrm{~min}^{-1}$ under a nitrogen flow of $50 \mathrm{~mL} \mathrm{~min}^{-1}$.

Solubility measurements. To a weighed sample of around $1 \mathrm{mg}$ was added $200 \mu \mathrm{L}$ of $o$-DCB, repeatedly. The resulting suspension was shaken and heated at $100{ }^{\circ} \mathrm{C}$ until complete dissolution. The total amount of solvent in $\mathrm{mL}$ was converted into solubility in $\mathrm{wt} \%$. 
1 X-ray crystallography. $\mathrm{PhC}_{2}-\mathrm{BQQDI}-\mathrm{C}_{n}$ single crystals were obtained by means of slow-

2 cooling over a period of 48 hours in a mixture of nitrobenzene and 1-methylnaphthalene, and

$3 \mathrm{PhC}_{2}-\mathrm{BQQDI}-\mathrm{C}_{5}$ crystals were grown in the mixture of nitrobenzene and 1-

4 chloronaphthalene. Single-crystal X-ray diffraction data were collected on either a Rigaku R-

5 AXIS RAPID II imaging plate diffractometer with $\mathrm{CuK} \alpha$ radiation $(\lambda=1.54187 \AA)$ or a Rigaku

6 XtaLAB Synergy-Custom instrument with $\mathrm{CuK \alpha}$ radiation $(\lambda=1.54184 \AA)$ at room

7 temperature. The structures were solved by direct methods [SHELXT (2015)] and refined by

8 full-matrix least-squares procedures on F2 for all reflections [SHELXL (Ver. 2014/7) or

9 SHELXL (Ver. 2018/3)]. While positions of all hydrogen atoms were calculated geometrically, and refined by applying riding model, all other atoms were refined anisotropically. Crystallographic data have been deposited in the Cambridge Crystallographic Data Centre as a supplementary publication. These data can be obtained free of charge at www.ccdc.cam.ac.uk/data_request/cif. The temperature-variant PXRD studies of $\mathrm{PhC}_{2}-$ BQQDI-C5 was carried out using the synchrotron X-ray powder diffraction with the wavelength of $0.8 \AA$ at BL44B2 at SPring- 8 RIKEN Materials Science Beamline $(\mathrm{BL} 44 \mathrm{~B} 2)^{49,50}$. Powders of $\mathrm{PhC}_{2}-\mathrm{BQQDI}-\mathrm{C}_{5}$ were packed in glass capillaries and the diffraction patterns are recorded in the temperature ranged from 25 to $200{ }^{\circ} \mathrm{C}$. The intensities of diffraction patterns at different temperatures were normalized for better comparison.

Preparation of OFET substrates. A highly $\mathrm{n}^{++}$-doped silicon wafer was used as the substrate, which the surface was treated by a fluorinated insulating polymer, AL-X601 (40 nm). The highly $\mathrm{n}^{++}$-doped silicon wafer with thermally grown $\mathrm{SiO}_{2}$ layer $(200 \mathrm{~nm})$ was ultrasonicated in acetone and isopropanol, and then dried on a hotplate in air. Following $\mathrm{UV}-\mathrm{O}_{3}$ treatment, AL-X601 diluted with propylene glycol monomethyl ether acetate (PGMEA) was spin-coated onto the wafer and cured at $150{ }^{\circ} \mathrm{C}$ for $30 \mathrm{~min}$ in an air.

Fabrication of solution-processed single-crystalline thin films. $\mathrm{PhC}_{2}-\mathrm{BQQDI}-\mathrm{C}_{n}$ were investigated in the bottom-gate, top-contact OFET structure. Preparations of single-crystalline thin films were carried out by the solution-processed edge-casting method ${ }^{53}$. Thin-film crystals of $\mathrm{PhC}_{2}-\mathrm{BQQDI}-\mathrm{C}_{n}$ were grown from $0.02-0.03 \mathrm{wt} \% 1-$ methylnaphthalene solutions at 90 $115^{\circ} \mathrm{C}$. After the completion of crystallization, thin films were thoroughly dried in a vacuum oven at $100{ }^{\circ} \mathrm{C}$ for 10 hours. Then, $40 \mathrm{~nm}$-thick gold layers were vacuum deposited through a metal shadow mask, acting as source and drain electrodes. Objective channel regions were edged by the conventional Nd:YAG laser etching technique or manually by using cotton swabs. 
1 Before measurements, thermal annealing at $100{ }^{\circ} \mathrm{C}$ for 10 hours were conducted to remove residual water and improve gold electrode-semiconductor contacts.

3 Fabrication of large-area single-crystalline thin films. The single-crystalline film of $\mathrm{PhC}_{2}-$ BQQDI-C 5 (0.02 wt\% in 1-methylnaphthalene) was prepared on a glass substrate encapsulated by a $55 \mathrm{~nm}$-thick AL-X601 insulating layer by means of the continuous edge-casting method. The stage temperature was maintained at $140{ }^{\circ} \mathrm{C}$ and the velocity of the moving stage was set to $24 \mu \mathrm{m} \mathrm{s}^{-1}$.

OFET measurements. Electrical evaluations of the TFTs were conducted on a Keithley 4200-

SCS semiconductor parameter analyzer in air. For AL-X601-containing gate dielectrics, the gate capacitance per unit area $\left(C_{\mathrm{i}}\right)$ was estimated using a Toyo FCE-3 ferroelectric test system on metal-insulator-metal structures. Electron mobility and threshold voltage were extracted from the transfer characteristics by using the conventional equation for the saturation regime:

$$
\sqrt{\left|I_{\mathrm{D}}\right|}=\sqrt{\frac{W \mu_{\mathrm{e}} C_{\mathrm{i}}}{2 L}}\left(V_{\mathrm{G}}-V_{\mathrm{th}}\right)
$$

where $I_{\mathrm{D}}$ is the drain current, $W$ the channel width, $\mu_{\mathrm{e}}$ the electron mobility, $C_{\mathrm{i}}$ the gate capacitance per unit area, $L$ the channel length, $V_{\mathrm{G}}$ the gate voltage, and $V_{\text {th }}$ the threshold voltage.

Molecular dynamic simulations. Molecular dynamics (MD) simulations of single crystal structures in this study were carried out by using the MD program GROMACS 2016.3. Since the intra- and interatomic interactions should be treated explicitly for analyzing the atomistic dynamics, an all-atom model was employed in accordance with generalized Amber force field parameters ${ }^{60}$. The partial atomic charges of the simulated molecules were calculated using the restrained electrostatic potential (RESP) ${ }^{61}$ methodology, based on DFT calculations with the 6-31G(d) basis set using the GAUSSIAN 09 program $^{59}$.

For each system, the pre-equilibration run was initially performed at the given temperature for $5 \mathrm{~ns}$ after the steepest descent energy minimization. All systems were subjected to preequilibration runs in the NTV ensemble before their equilibration runs. During the preequilibration runs for the NTV ensemble, the Berendsen thermostat ${ }^{62}$ was used to maintain the temperature of the system with relaxation time of $0.2 \mathrm{ps}$ and the volume of the MD cell was kept constant. Subsequently, for the NTP ensemble the equilibration run was performed using the Nosé-Hoover thermostat ${ }^{63-65}$ and Parrinello-Rahman barostat ${ }^{66}$ with relaxation times of 1.0 and $5.0 \mathrm{ps}$, respectively. For all MD simulations in the NTP ensemble, the pressure of the 
1 system was kept at 1.0 bar. The smooth particle-mesh Ewald (PME) ${ }^{67}$ method was employed to treat the long-rang electrostatic interactions and the real space cutoff and the grid spacing are 1.2 and $0.30 \mathrm{~nm}$, respectively. The time step was set to $1 \mathrm{fs}$. To compare temperature dependence of thermal atomic fluctuations between different molecules, we calculated the B-factors related to the thermal stability as expressed below:

$$
B=\frac{8}{3} \pi^{2} \Delta_{i}^{2}
$$

where $\Delta_{i}$ is the root mean square fluctuations (RMSF) of atom $i$. The RMSF values can be estimated by using following equation:

$$
\Delta_{i}=\sqrt{\frac{1}{T} \sum_{j=1}^{T}\left|\boldsymbol{r}_{i}\left(t_{j}\right)-\overline{\boldsymbol{r}}_{i}\right|^{2}}
$$

10 where $T$ is the time step, $\boldsymbol{r}_{i}\left(t_{j}\right)$ is the position coordinate of atom $i$, and $\overline{\boldsymbol{r}}_{i}$ is the average of $\boldsymbol{r}_{i}\left(t_{j}\right)$. The RMSF values were analyzed from MD trajectories during the last $10 \mathrm{~ns}$ in the equilibrium.

\section{Data availability}

The data reported in this study are available from the corresponding author (Toshihiro Okamoto; tokamoto@k.u-tokyo.ac.jp) upon reasonable requests. Crystallographic data have been deposited in the Cambridge Crystallographic Data Centre (CCDC) as a supplementary publication under accession nos. CCDC-1989643 ( PhC $_{2}-\mathrm{BQQDI}-\mathrm{C}_{5}, 298 \mathrm{~K}$ ), CCDC-1989644 ( $\left.\mathrm{PhC}_{2}-\mathrm{BQQDI}-\mathrm{C}_{6}, 298 \mathrm{~K}\right), \mathrm{CCDC}-1989645$ ( $\left.\mathrm{PhC}_{2}-\mathrm{BQQDI}-\mathrm{C}_{7}, 293 \mathrm{~K}\right)$. These data can be obtained free of charge at www.ccdc.cam.ac.uk/data_request/cif.

\section{References}

1. Kato, T. et al. Transport of ions and electrons in nanostructured liquid crystals. Nat. Rev. Mater. 2, 17001 (2017).

2. Lipowsky, R. The conformation of membranes. Nature 349, 475-481 (1991).

3. Coropceanu, V. et al. Charge transport in organic semiconductors. Chem. Rev. 107, 926-952 (2007).

4. Podzorov, V. et al. Intrinsic charge transport on the surface of organic semiconductors. Phys. Rev. Lett. 93, 086602 (2004). 
1 5. Podzorov, V., Menard, E., Rogers, J. A. \& Gershenson, M. E. Hall effect in the accumulation layers on the surface of organic semiconductors. Phys. Rev. Lett. 95, 226601 (2005).

6. Takeya, J., Tsukagoshi, K., Aoyagi, Y., Takenobu, T. \& Iwasa, Y. Hall effect of quasihole gas in organic single-crystal transistors. Jpn. J. Appl. Phys. 44, 1393 (2005).

7. Fratini, S., Nikolka, M., Salleo, A., Schweicher, G. \& Sirringhaus, H. Charge transport in high-mobility conjugated polymers and molecular semiconductors. Nat. Mater. 19, 491-502 (2020).

8. Yamamura, A. et al. Wafer-scale, layer-controlled organic single crystals for highspeed circuit operation. Sci. Adv. 4, eaao5758 (2018).

9. Zheng, J., Kwak, K., Xie, J. \& Fayer, M. D. Ultrafast carbon-carbon single-bond rotational isomerization in room-temperature solution. Science 313, 1951-1955 (2006).

10. Su, S. Q. et al. Assembling an alkyl rotor to access abrupt and reversible crystalline deformation of a cobalt(II) complex. Nat. Commun. 6, 8810 (2015).

11. Eggeman, A. S., Illig, S., Troisi, A., Sirringhaus, H. \& Midgley, P. A. Measurement of molecular motion in organic semiconductors by thermal diffuse electron scattering. Nat. Mater. 12, 1045-1049 (2013).

12. Illig, S. et al. Reducing dynamic disorder in small-molecule organic semiconductors by suppressing large-Amplitude thermal motions. Nat. Commun. 7, 10736 (2016).

13. Kubo, T. et al. Suppressing molecular vibrations in organic semiconductors by inducing strain. Nat. Commun. 7, 11156 (2016).

14. Tsurumi, J. et al. Coexistence of ultra-long spin relaxation time and coherent charge transport in organic single-crystal semiconductors. Nat. Phys. 13, 994-998 (2017).

15. Fratini, S., Ciuchi, S., Mayou, D., De Laissardière, G. T. \& Troisi, A. A map of highmobility molecular semiconductors. Nat. Mater. 16, 998-1002 (2017).

16. Schweicher, G. et al. Chasing the "Killer" Phonon Mode for the Rational Design of Low-Disorder, High-Mobility Molecular Semiconductors. Adv. Mater. 31, 1902407 (2019).

17. Feldblum, E. S. \& Arkin, I. T. Strength of a bifurcated H bond. Proc. Natl. Acad. Sci. 
U.S.A. 111, 4085-4090 (2014).

18. Trembleau, L. \& Rebek, J. Helical conformation of alkanes in a hydrophobic cavitand. Science 301, 1219-1220 (2003).

19. Purse, B. W. \& Rebek, J. Self-fulfilling cavitands: Packing alkyl chains into small spaces. Proc. Natl. Acad. Sci. U.S.A. 103, 2530-2534 (2006).

20. Ajami, D. \& Rebek, J. Compressed alkanes in reversible encapsulation complexes. Nat. Chem. 1, 87-90 (2009).

21. Smits, E. C. P. et al. Bottom-up organic integrated circuits. Nature 455, 956-959 (2008).

22. Molinari, A. S., Alves, H., Chen, Z., Facchetti, A. \& Morpurgo, A. F. High electron mobility in vacuum and ambient for PDIF-CN2 single-crystal transistors. J. Am. Chem. Soc. 131, 2462-2463 (2009).

23. Liang, Z., Tang, Q., Xu, J. \& Miao, Q. Soluble and stable N-heteropentacenes with high field-effect mobility. Adv. Mater. 23, 1535-1539 (2011).

24. Yu, C. P. et al. Air-Stable Benzo[c]thiophene Diimide n-Type $\pi$-Electron Core. Org. Lett. 21, 4448-4453 (2019).

25. Vladimirov, I. et al. High-Mobility, Ultrathin Organic Semiconducting Films Realized by Surface-Mediated Crystallization. Nano Lett. 18, 9-14 (2018).

26. Ebata, H. et al. Highly soluble [1]benzothieno[3,2-b]benzothiophene (BTBT) derivatives for high-performance, solution-processed organic field-effect transistors. $J$. Am. Chem. Soc. 129, 15732-15733 (2007).

27. Yamamoto, T. \& Takimiya, K. Facile synthesis of highly $\pi$-extended heteroarenes, dinaphtho[2,3-b: 2',3'-f]chalcogenopheno[3,2-b]chalcogenophenes, and their application to field-effect transistors. J. Am. Chem. Soc. 129, 2224-2225 (2007).

28. Nakayama, K. et al. Patternable solution-crystallized organic transistors with high charge carrier mobility. Adv. Mater. 23, 1626-1629 (2011).

29. Okamoto, T. et al. V-shaped organic semiconductors with solution processability, high mobility, and high thermal durability. Adv. Mater. 25, 6392-6397 (2013).

30. Mitsui, C. et al. High-performance solution-processable N-shaped organic semiconducting materials with stabilized crystal phase. Adv. Mater. 26, 4546-4551 
(2014).

31. Yamamoto, A. et al. Zigzag-Elongated Fused $\pi$-Electronic Core: A Molecular Design Strategy to Maximize Charge-Carrier Mobility. Adv. Sci. 5, 1700317 (2018).

32. Okamoto, T. et al. Bent-Shaped p-Type Small-Molecule Organic Semiconductors: A Molecular Design Strategy for Next-Generation Practical Applications. J. Am. Chem. Soc. 142, 9083-9096 (2020).

33. Okamoto, T. et al. Robust, high-performance n-type organic semiconductors. Sci. Adv. 6, eaaz0632 (2020).

34. Kumagai, S. et al. Cooperative Aggregations of Nitrogen-Containing Perylene Diimides Driven by Rigid and Flexible Functional Groups. Chem. Mater. 32, 9115$9125(2020)$.

35. Kumagai, S. et al. Coherent Electron Transport in Air-Stable, Printed Single-Crystal Organic Semiconductor and Application to Megahertz Transistors. Adv. Mater. 2003245 (2020).

36. Jones, B. A., Facchetti, A., Wasielewski, M. R. \& Marks, T. J. Tuning orbital energetics in arylene diimide semiconductors. Materials design for ambient stability of n-type charge transport. J. Am. Chem. Soc. 129, 15259-15278 (2007).

37. Rivnay, J. et al. Large modulation of carrier transport by grain-boundary molecular packing and microstructure in organic thin films. Nat. Mater. 8, 952-958 (2009).

38. Gsänger, M. et al. A crystal-engineered hydrogen-bonded octachloroperylene diimide with a twisted core: An n-channel organic semiconductor. Angew. Chem. Int. Ed. 49, 740-743 (2010).

39. Soeda, J. et al. Inch-size solution-processed single-crystalline films of high-mobility organic semiconductors. Appl. Phys. Express 6, 076503 (2013).

40. Kumagai, S. et al. Scalable Fabrication of Organic Single-Crystalline Wafers for Reproducible TFT Arrays. Sci. Rep. 9, 15897 (2019).

41. Van Potter, R. \& Heidelberger, C. Biosynthesis of asymmetric citric acid: A substantiation of the Ogston concept. Nature 164, 180-181 (1949).

42. Sample, C. S. et al. Modular synthesis of asymmetric rylene derivatives. J. Mater. Chem. C 5, 1052-1056 (2017). 
43. Che, Y., Datar, A., Balakrishnan, K. \& Zang, L. Ultralong nanobelts self-assembled from an asymmetric perylene tetracarboxylic diimide. J. Am. Chem. Soc. 129, 72347235 (2007).

44. Xue, C., Sun, R., Annab, R., Abadi, D. \& Jin, S. Perylene monoanhydride diester: a versatile intermediate for the synthesis of unsymmetrically substituted perylene tetracarboxylic derivatives. Tetrahedron Lett. 50, 853-856 (2009).

45. Gupta, R. K. \& Achalkumar, A. S. Microwave-Assisted Method for the Synthesis of Perylene Ester Imides as a Gateway Toward Unsymmetrical Perylene Bisimides. $J$. Org. Chem. 83, 6290-6300 (2018).

46. Mancini, R. S., Lee, J. B. \& Taylor, M. S. Boronic esters as protective groups in carbohydrate chemistry: processes for acylation, silylation and alkylation of glycosidederived boronates. Org. Biomol. Chem. 15, 132-143 (2017).

47. Ueda, T., Konishi, H. \& Manabe, K. Trichlorophenyl formate: Highly reactive and easily accessible crystalline $\mathrm{CO}$ surrogate for palladium-catalyzed carbonylation of aryl/alkenyl halides and triflates. Org. Lett. 14, 5370-5373 (2012).

48. Usta, H., Facchetti, A. \& Marks, T. J. n-channel semiconductor materials design for organic complementary circuits. Acc. Chem. Res. 44, 501-510 (2011).

49. Kato, K. \& Tanaka, H. Visualizing charge densities and electrostatic potentials in materials by synchrotron X-ray powder diffraction. Adv. Phys. X 1, 55-80 (2016).

50. Kato, K., Tanaka, Y., Yamauchi, M., Ohara, K. \& Hatsui, T. A statistical approach to correct $\mathrm{x}$-ray response non-uniformity in microstrip detectors for high-accuracy and high-resolution total-scattering measurements. J. Synchrotron Radiat. 26, 762-773 (2019).

51. Iino, H., Usui, T. \& Hanna, J. I. Liquid crystals for organic thin-film transistors. Nat. Commun. 6, 6828 (2015).

52. Inoue, S. et al. Effects of Substituted Alkyl Chain Length on Solution-Processable Layered Organic Semiconductor Crystals. Chem. Mater. 27, 3809-3812 (2015).

53. Uemura, T., Hirose, Y., Uno, M., Takimiya, K. \& Takeya, J. Very high mobility in solution-processed organic thin-film transistors of highly ordered [1]benzothieno[3,2b]benzothiophene derivatives. Appl. Phys. Express 2, 111501 (2009). 
1 54. Choi, H. H., Cho, K., Frisbie, C. D., Sirringhaus, H. \& Podzorov, V. Critical assessment of charge mobility extraction in FETs. Nat. Mater. 17, 2-7 (2017).

55. Fukami, T. et al. Correlation between thermal fluctuation effects and phase coherence factor in carrier transport of single-crystal organic semiconductors. Appl. Phys. Lett. 106, (2015).

56. Yamagiwa, N., Okabe, T., Suto, Y. \& Iwasaki, G. Acidic solvent-free removal of amine-protecting diphenylmethyl groups in the presence of camphorsulfonic acid. Chem. Lett. 46, 1456-1458 (2017).

57. Schmidt, M. W. et al. General atomic and molecular electronic structure system. $J$. Comput. Chem. 14, 1347-1363 (1993).

58. Boys, S. F. \& Bernardi, F. The calculation of small molecular interactions by the differences of separate total energies. Some procedures with reduced errors. Mol. Phys. 19, 553-566 (1970).

59. Frisch, M. J. et al. Gaussian 09, Revision A.02. Gaussian 09, Revision A.02 (2009).

60. Wang, J., Wolf, R. M., Caldwell, J. W., Kollman, P. A. \& Case, D. A. Development and testing of a general Amber force field. J. Comput. Chem. 25, 1157-1174 (2004).

61. Bayly, C. I., Cieplak, P., Cornell, W. D. \& Kollman, P. A. A well-behaved electrostatic potential based method using charge restraints for deriving atomic charges: The RESP model. J. Phys. Chem. 97, 10269-10280 (1993).

62. Berendsen, H. J. C., Postma, J. P. M., Van Gunsteren, W. F., Dinola, A. \& Haak, J. R. Molecular dynamics with coupling to an external bath. J. Chem. Phys. 81, 3684-3690 (1984).

63. Nosé, S. A unified formulation of the constant temperature molecular dynamics methods. J. Chem. Phys. 81, 511-519 (1984).

64. Nosé, S. A molecular dynamics method for simulations in the canonical ensemble. Mol. Phys. 52, 255-268 (1984).

65. Hoover, W. G. Canonical dynamics: Equilibrium phase-space distributions. Phys. Rev. A 31, 1695-1697 (1985).

66. Parrinello, M. \& Rahman, A. Polymorphic transitions in single crystals: A new molecular dynamics method. J. Appl. Phys. 52, 7182-7190 (1981). 
1 67. Darden, T., York, D. \& Pedersen, L. Particle mesh Ewald: An $N \cdot \log (\mathrm{N})$ method for Ewald sums in large systems. J. Chem. Phys. 98, 10089-10092 (1993).

\section{Acknowledgements}

4 The authors thank AGC Inc. for supplying AL-X601. The computation reported in this paper was performed at the Research Center for Computational Science, Okazaki, Japan. The authors thank Mr. Kazuya Shigeta and Dr. Kenichi Kato at RIKEN SPring-8 Center for their skilled technical contributions and fruitful discussions. The temperature-variant experiments were performed under the approval of RIKEN (Proposal Nos. 20180049 and 20190046). This work was supported by the JST-PRESTO program "Scientific Innovation for Energy Harvesting Technology" (number JPMJPR17R2) and by KAKENHI. C.P.Y thanks the Grant-in-Aid for JSPS Fellows (number JP20J12608), T.O., H.I., and G.W. thank JSPS for Grants-in-Aid for Scientific Research, B (numbers JP17H03104, JP18H01856, JP19H02537) and on Innovative Areas (JP19H05718).

\section{Author contributions}

T.O. conceived and designed the work, while C.P.Y., S.K., M.T., T.K., H.S., Y.T., T.I., and

\section{Competing interests}

24 The authors declare no competing interests. 
Figures

a

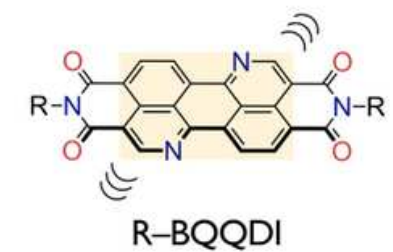

$\checkmark$ Deep $E_{\text {LUMO }}=-4.17 \mathrm{eV}$

$\checkmark$ Lateral hydrogen bonding

$\checkmark$ 2D charge transport

$\checkmark$ Air-stable n-type OSC

$\checkmark$ Suppressed molecular fluctuations

b

$$
\mathrm{PhC}_{2}-\mathrm{BQQDI}\left(\mathrm{R}=-\mathrm{C}_{2} \mathrm{H}_{4} \mathrm{Ph}\right)
$$

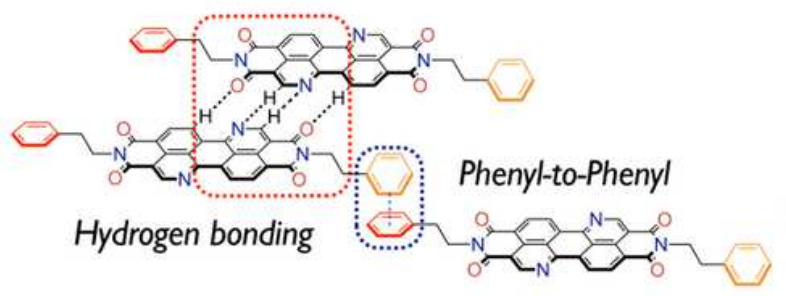

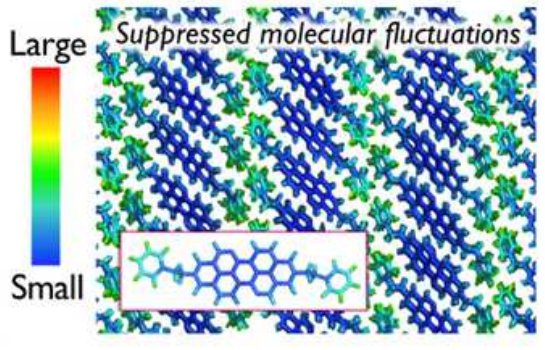

C
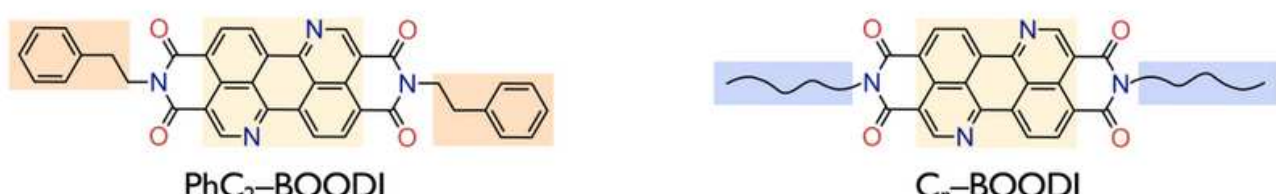

$\mathrm{PhC}_{2}-\mathrm{BQQDI}$

$\mathrm{C}_{n}-\mathrm{BQQDI}$

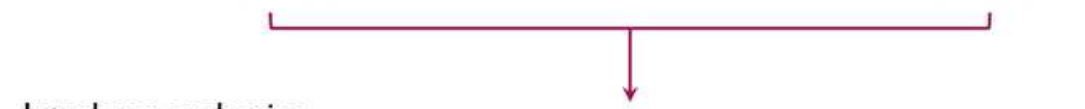

Interlayer anchoring

via $\mathrm{C}-\mathrm{H} \cdots \pi$

tor

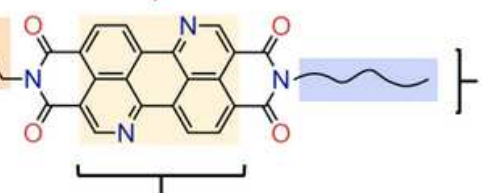

Tuning of molecular assemblies

BQQ $\pi$-core

$\mathrm{PhC}_{2}-\mathrm{BQQDI}^{-\mathrm{C}_{n}}$

\section{Figure 1}

General molecular features. a Molecular structure and features of BQQDI. b Molecular assembly and fluctuations of PhC2-BQQDI. c Molecular design of asymmetric PhC2-BQQDI-Cn (Cn: linear alkyl chains, $\mathrm{n}-\mathrm{CnH} 2 \mathrm{n}+1)$. 
$\mathrm{PhC}_{2}-\mathrm{NH}_{2}$ PMB Protection

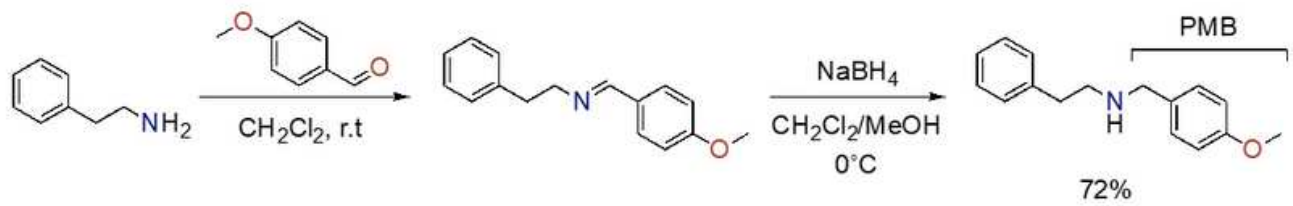

$\mathrm{PhC}_{2}-\mathrm{BQQDI}-\mathrm{C}_{n}$ Synthesis

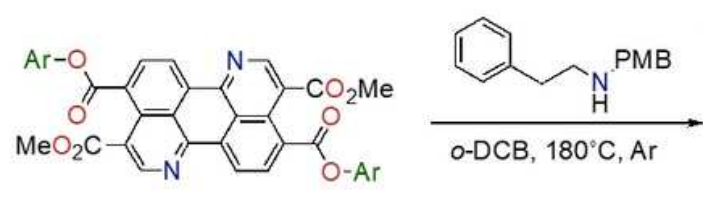

1<smiles>Clc1cc(Cl)c(I=[Zn])c(Cl)c1</smiles>

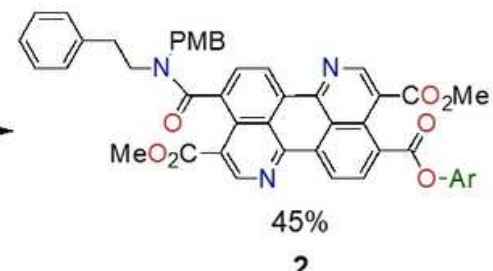

2
1. $\begin{gathered}\mathrm{R}-\mathrm{NH}_{2} \\ \text { o-DCB, } 150^{\circ} \mathrm{C}\end{gathered}$
2. $\mathrm{TfOH}, 150^{\circ} \mathrm{C}$

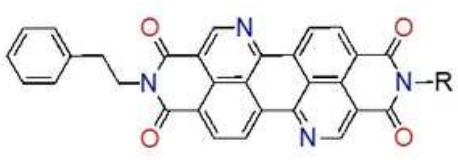

$\mathrm{PhC}_{2}-\mathrm{BQQDI}-\mathrm{C}_{n}$

$\mathrm{PhC}_{2}-\mathrm{BQQDI}-\mathrm{C}_{5}, 91 \%$

$\mathrm{PhC}_{2}-\mathrm{BQQDI}-\mathrm{C}_{6}, 90 \%$

$\mathrm{PhC}_{2}-\mathrm{BQQDI}-\mathrm{C}_{7}, 92 \%$

Figure 2

Synthesis of PhC2-BQQDI-Cn. Preparation of PMB-protected phenethylamine, and synthesis of PhC2BQQDI-Cn ( $n=5,6$, and 7). 
a

$\checkmark$ Molecular Mimicry

$\checkmark$ Gauche conformation

2D brickwork packing

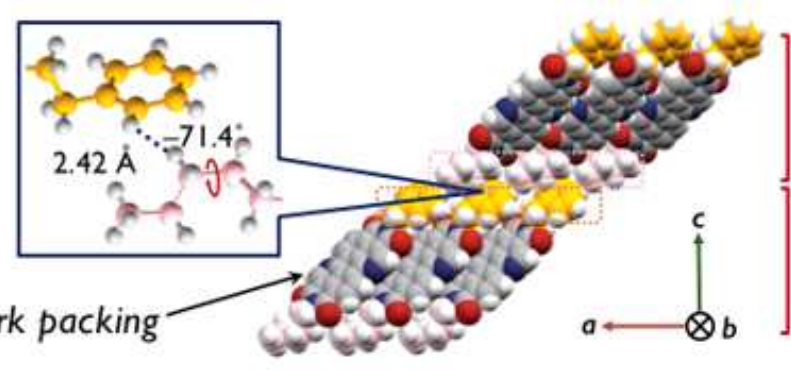

$\mathrm{PhC}_{2}-\mathrm{BQQDI}_{5}$
Layer

$\checkmark$ Layer-by-layer assembly

$\checkmark$ Phenyl-to-alkyl interactions

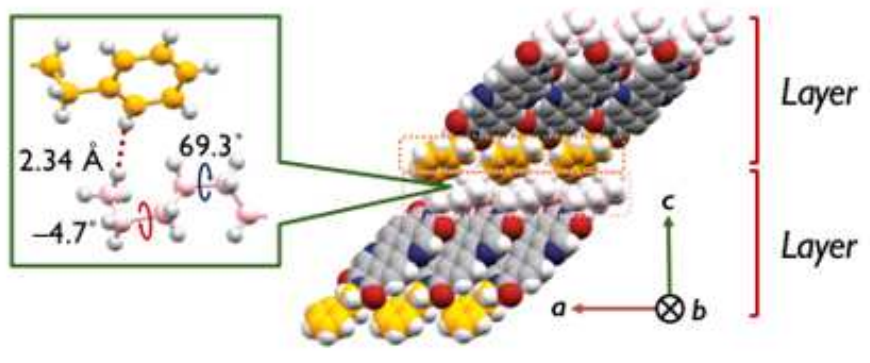

$\mathrm{PhC}_{2}-\mathrm{BQQDI} \mathrm{C}_{6}$

b

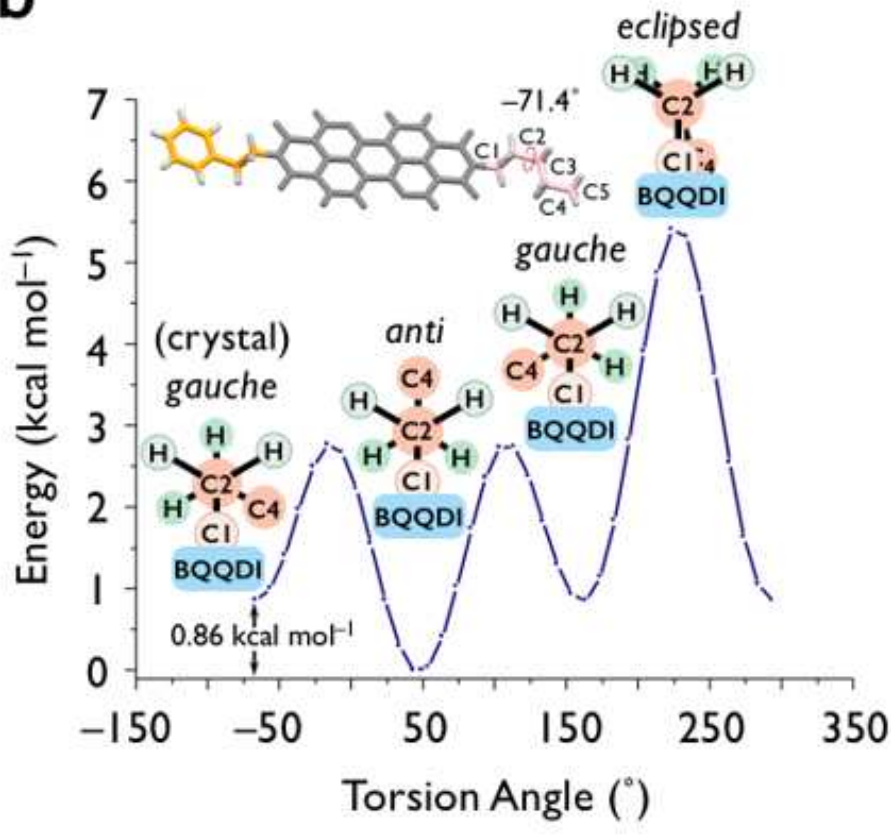

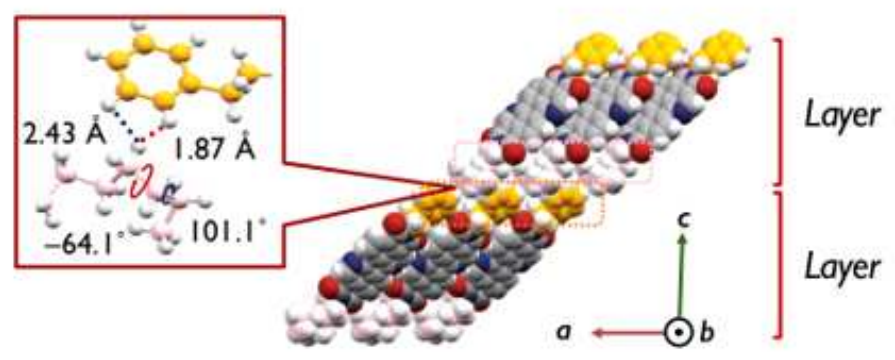

$\mathrm{PhC}_{2}-\mathrm{BQQDI}_{-\mathrm{C}_{7}}$

C

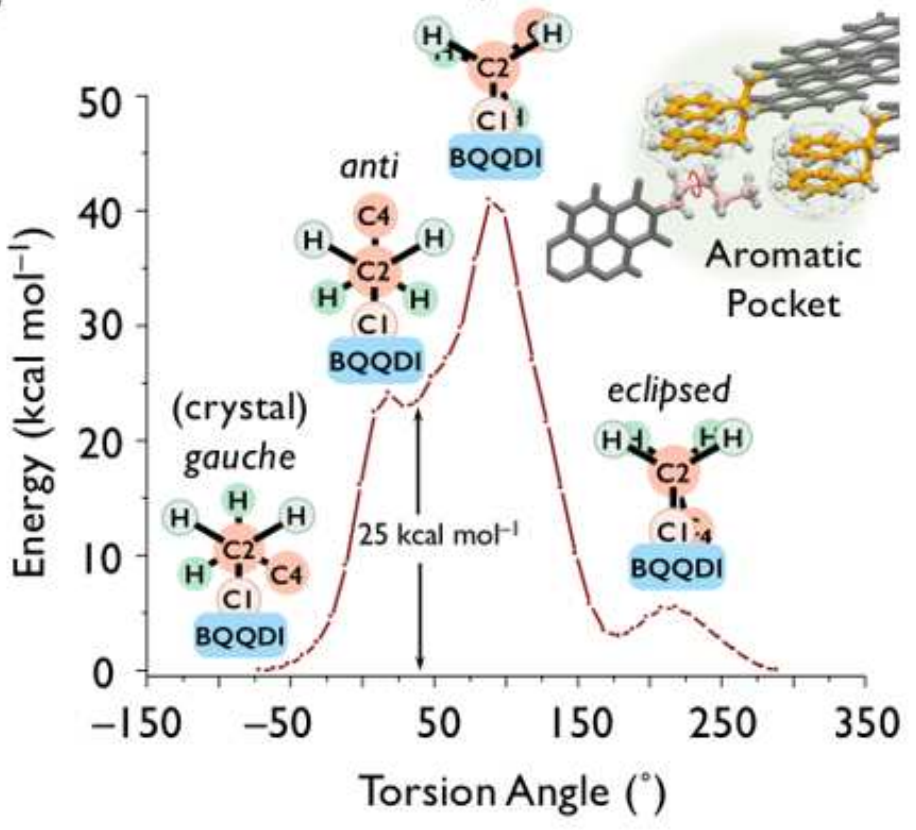

Figure 3

Molecular assemblies and alkyl chain conformations. a Packing structures and interlayer interactions of $\mathrm{PhC2}-\mathrm{BQQDI}-\mathrm{Cn} . \mathrm{b}-\mathrm{c}$ Torsion angle energy scans $\left(\mathrm{C} 2-\mathrm{C} 3\right.$, starting from $\left.-71.4^{\circ}\right)$ of PhC2-BQQDI-C5 monomer and pentamer (structures from the single crystal) at the B3LYP/6-31G+(d) level of theory. 
a

2D brickwork packing motif

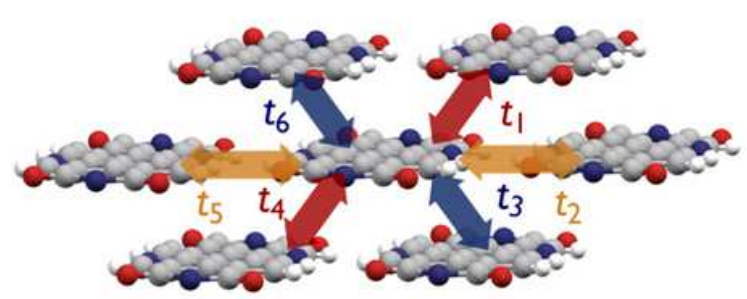

\begin{tabular}{l|c|c|c} 
& $t_{1}, t_{4}$ & $t_{3}, t_{6}$ & $t_{2}, t_{5}$ \\
\hline $\mathrm{PhC}_{2}-\mathrm{BQQDI}-\mathrm{C}_{5}$ & $+53.2 \mathrm{meV}$ & $+81.1 \mathrm{meV}$ & $+18.1 \mathrm{meV}$ \\
\hline $\mathrm{PhC}_{2}-\mathrm{BQQDI}_{-} \mathrm{C}_{6}$ & $+55.4 \mathrm{meV}$ & $+83.8 \mathrm{meV}$ & $+17.3 \mathrm{meV}$ \\
\hline $\mathrm{PhC}_{2}-\mathrm{BQQDI}-\mathrm{C}_{7}$ & $+54.7 \mathrm{meV}$ & $+85.6 \mathrm{meV}$ & $+17.9 \mathrm{meV}$
\end{tabular}

b

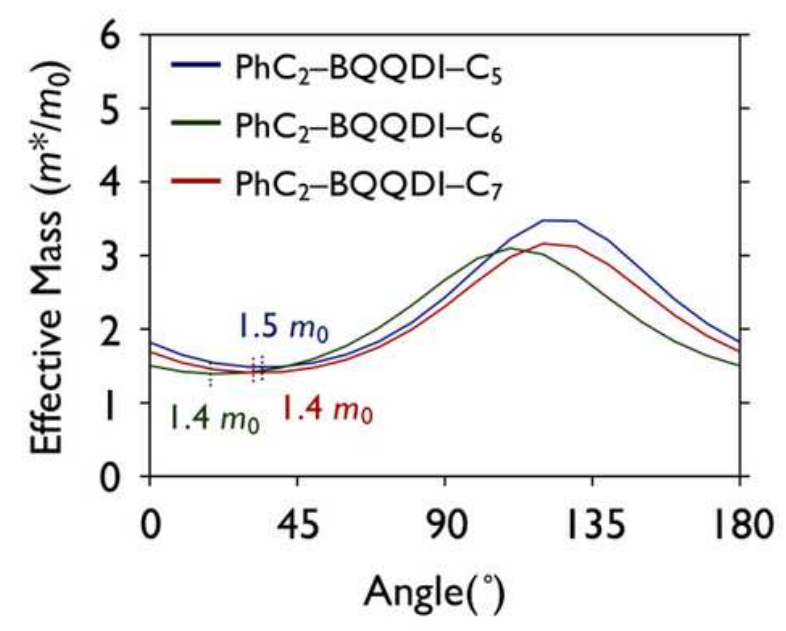

C

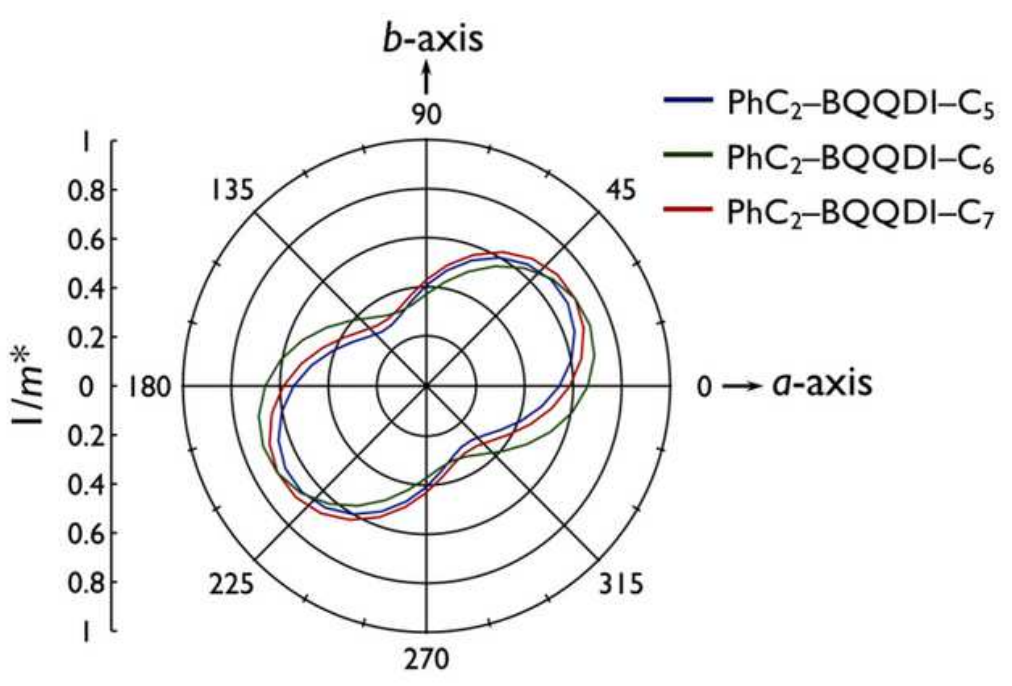

Figure 4

Charge-transport capability of PhC2-BQQDI-Cn. a Transfer integral $(\mathrm{t})$ in the 2D brickwork packing motif calculated at the PBEPBE/6-31G(d) level of theory. b-c Effective mass and angle-dependent inversed effective mass (relative to crystallography axes) by the tight-binding approximation, respectively. 

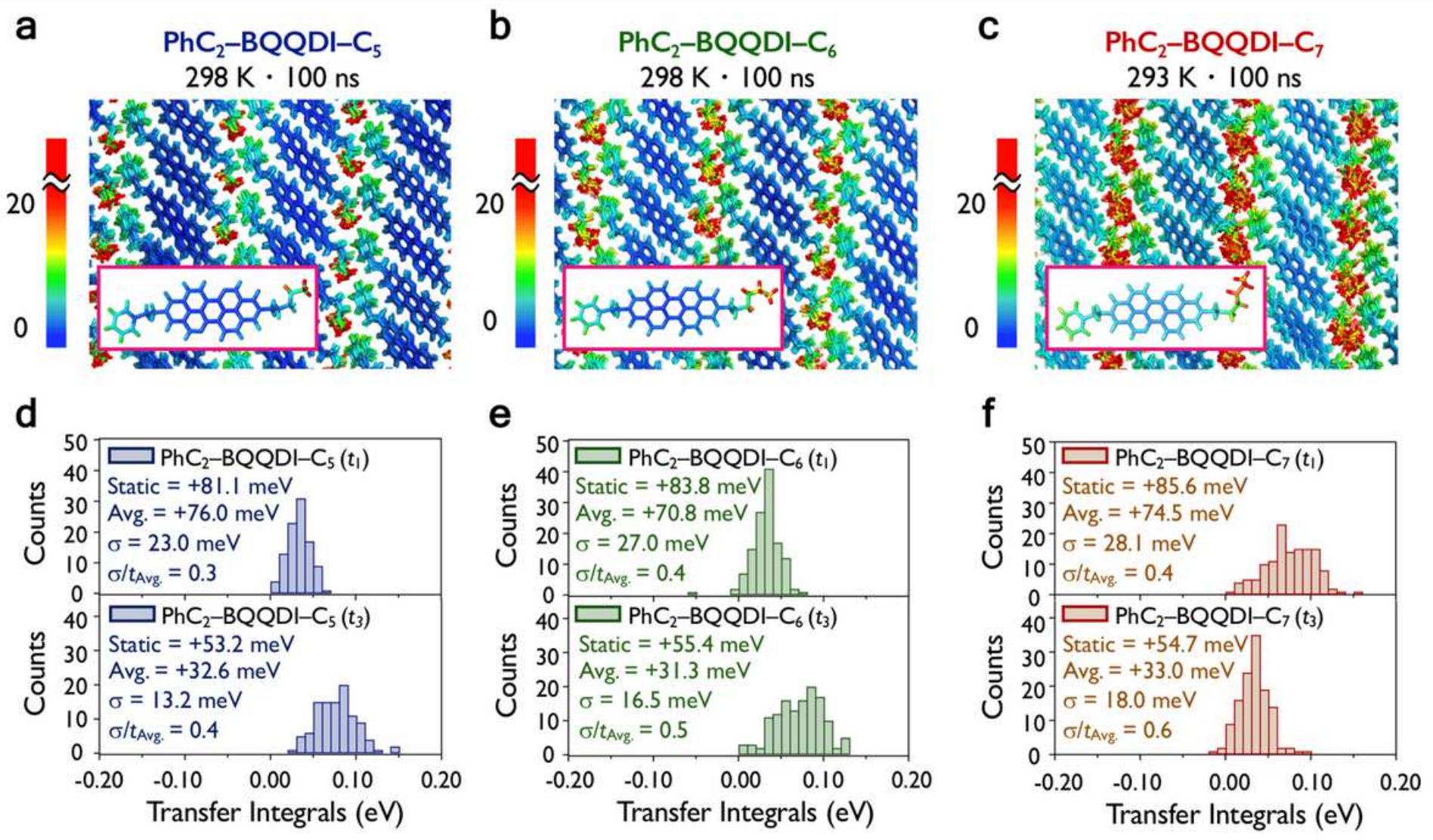

Figure 5

Molecular fluctuations by MD simulations. a-c Color-coded B-factor ( $\AA 2$ s-1) distribution of PhC2BQQDI-Cn ( $n=5,6$, and 7) obtained from the trajectories during the last 10 ns of a $100 \mathrm{~ns}$ MD simulations in the NTP ensemble and variant transfer integrals ( $\mathrm{t} 1$ and $\mathrm{t} 3$ ) at $100 \mathrm{~ns}$ of the MD simulations. $d-f$ Variant $t$ value distributions and standard deviations $(\sigma)$ revealing the magnitude of the dynamic fluctuations. 
a

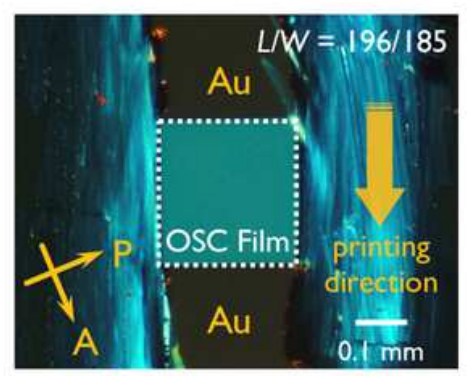

b

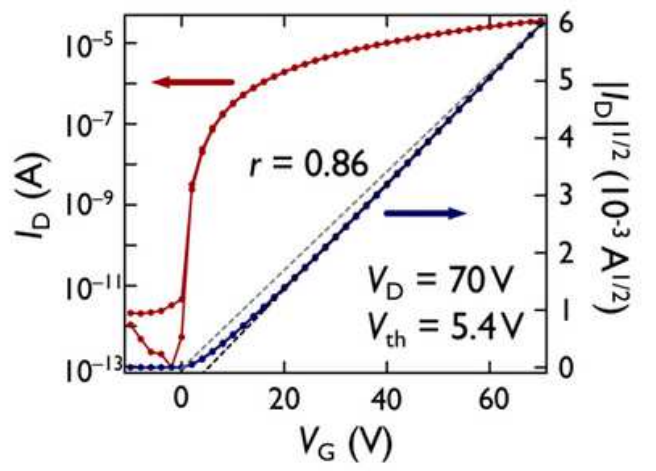

C

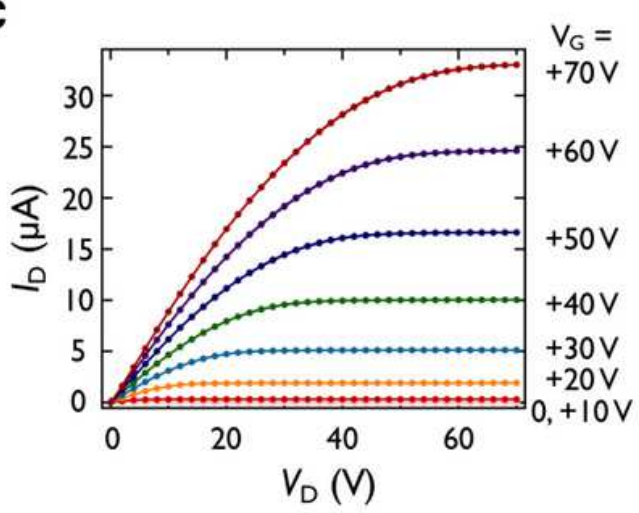

d

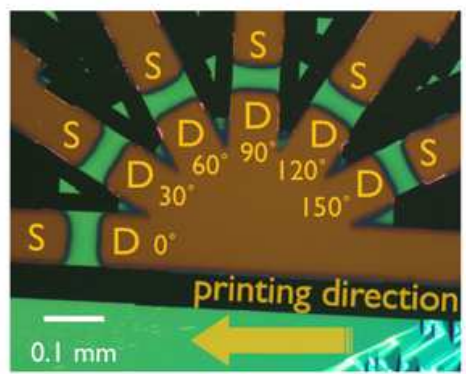

e

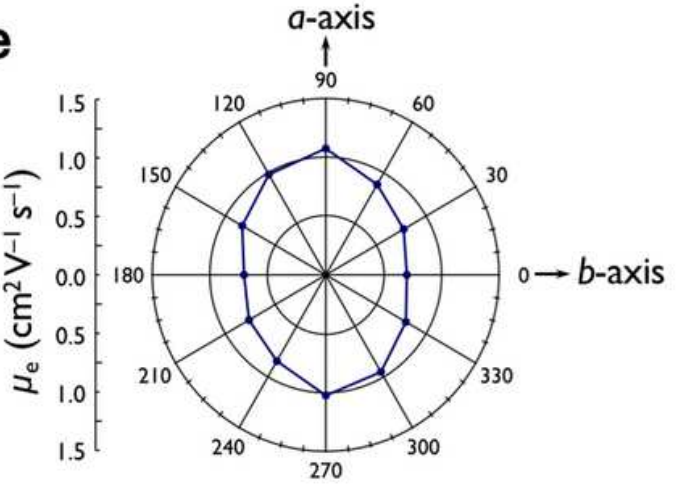

Figure 6

OFET performances of $\mathrm{PhC2} \neg-\mathrm{BQQDI}-\mathrm{C} 5$. a-c Polarized microscopic image of single-crystalline thinfilm OFET, transfer (black and gray dashed lines represent the fit to |ID|1/2 and the slope of an electrically ideal OFET54, respectively) and output characteristics evaluated under ambient conditions. d-e Fanshaped OFETs on the inch-scale single-crystalline thin film with channels in every $30^{\circ}$ relative to the printing direction $(\mathrm{L}=\sim 40 \mu \mathrm{m}, \mathrm{W}=\sim 90 \mu \mathrm{m})$, and the resulting azimuthal $\mu \mathrm{e}$.

\section{Supplementary Files}

This is a list of supplementary files associated with this preprint. Click to download.

- PhC2BQQDICnSINatureCommun210224v9.docx

- PhC2BQQDIC5.cif

- PhC2BQQDIC6.cif

- PhC2BQQDIC7.cif 